\title{
A high-resolution ocean and sea-ice modelling system for the Arctic and North Atlantic oceans
}

\author{
F. Dupont ${ }^{1}$, S. Higginson ${ }^{3}$, R. Bourdallé-Badie ${ }^{4}$, Y. Lu ${ }^{3}$, F. Roy ${ }^{2}$, G. C. Smith ${ }^{2}$, J.-F. Lemieux ${ }^{2}$, G. Garric ${ }^{4}$, and \\ F. Davidson ${ }^{5}$ \\ ${ }^{1}$ Service météorologique du Canada, Environnement Canada, Dorval, QC, Canada \\ ${ }^{2}$ Recherche en Prévision Environnementale, Environnement Canada, Dorval, QC, Canada \\ ${ }^{3}$ Bedford Institute of Oceanography, Fisheries and Oceans Canada, Dartmouth, NS, Canada \\ ${ }^{4}$ Mercator Océan, Toulouse, France \\ ${ }^{5}$ Northwest Atlantic Fisheries Centre, Fisheries and Oceans Canada, St. John's, NL, Canada \\ Correspondence to: F. Dupont (frederic.dupont@ec.gc.ca)
}

Received: 18 November 2014 - Published in Geosci. Model Dev. Discuss.: 5 January 2015

Revised: 21 April 2015 - Accepted: 24 April 2015 - Published: 28 May 2015

\begin{abstract}
As part of the CONCEPTS (Canadian Operational Network of Coupled Environmental PredicTion Systems) initiative, a high-resolution $\left(1 / 12^{\circ}\right)$ ice-ocean regional model is developed covering the North Atlantic and the Arctic oceans. The long-term objective is to provide Canada with short-term ice-ocean predictions and hazard warnings in ice-infested regions. To evaluate the modelling component (as opposed to the analysis - or data-assimilation - component, which is not covered in this contribution), a series of hindcasts for the period 2003-2009 is carried out, forced at the surface by the Canadian GDPS reforecasts (Smith et al., 2014). These hindcasts test how the model represents upper ocean characteristics and ice cover. Each hindcast implements a new aspect of the modelling or the ice-ocean coupling. Notably, the coupling to the multi-category ice model CICE is tested. The hindcast solutions are then assessed using a verification package under development, including in situ and satellite ice and ocean observations. The conclusions are as follows: (1) the model reproduces reasonably well the time mean, variance and skewness of sea surface height; (2) the model biases in temperature and salinity show that while the mean properties follow expectations, the $\mathrm{Pa}$ cific Water signature in the Beaufort Sea is weaker than observed; (3) the modelled freshwater content of the Arctic agrees well with observational estimates; (4) the distribution and volume of the sea ice are shown to be improved in the latest hindcast due to modifications to the drag coefficients and to some degree to the ice thickness distribution available
\end{abstract}

in CICE; (5) nonetheless, the model still overestimates the ice drift and ice thickness in the Beaufort Gyre.

\section{Introduction}

The CONCEPTS (Canadian Operational Network of Coupled Environmental PredicTion Systems) initiative has fostered collaborations between different federal departments (Fisheries and Oceans Canada, Environment Canada and the Department of National Defence) that yielded the development of several operational prediction systems. These include a coupled (atmosphere-ice-ocean) Gulf of Saint Lawrence system (officially operational since June 2011; Smith et al., 2012), the Global Ice-Ocean Prediction System (GIOPS, runs in real time since March 2014; Smith et al., 2015), a Great Lakes coupled system (still in development; Dupont et al., 2012), a regional ice-only prediction system (runs in real time since July 2013; Lemieux et al., 2015a) and a regional Arctic-North Atlantic ice-ocean system based on the CREG12 (Canadian REGional) configuration with a nominal horizontal resolution of $1 / 12^{\circ}$. The last is the focus of this paper. The GIOPS, Great Lakes and CREG12-based systems are based on NEMO (Nucleus for European Modelling of the Ocean, http://www.nemo-ocean.eu), while the coupled Gulf of Saint Lawrence system has just been transitioned to NEMO for the ice-ocean component. The develop- 
ment of these systems has benefited greatly from a collaboration with Mercator Océan in France.

The goal of the regional system based on CREG12 is to provide Canada with short-term ice-ocean predictions and analyses covering parts of the North Atlantic and whole Arctic oceans at high resolution. For this purpose, the regional system will eventually be coupled to the regional weather prediction system and wave prediction system of Environment Canada. The coupled system is expected to improve regional weather and marine forecasting services by, for example, issuing bulletins and warnings in ice-infested waters for navigation, energy exploration and northern communities' requirements. As such, the system development has benefited from financial support from the Canadian METAREA programme and the Beaufort Regional Environmental Assessment (BREA) project. However, before the full system (analysis plus forecast) can be approved for operational use, we need to understand how to use the ice-ocean forecasting component to its full potential, following the best practices of the community running at comparable resolutions. Hence, a series of hindcasts was performed using the iceocean model, each implementing and testing a different aspect of ice-ocean modelling. Implementation of data assimilation in this prediction system, adopting the same methodology as in Smith et al. (2015), is under development and will be reported in follow-up contributions.

These hindcasts are not long enough to test the full robustness of the model in preserving observed water and ice properties at climatic scales (i.e., several decades), as the initial conditions still imprint the model state after 8 years. Nevertheless, discrepancies between atmospheric forcing products and differences in upper-ocean and ice physics are sufficient to create diverging upper-ocean and ice states and variabilities in this short period that are worth investigating. Moreover, recent satellite missions and extensive and automated observing in situ programmes (ARGO floats and ice-tethered profilers to cite a few) create a wealth of data covering the hindcast period, which we take advantage of in our evaluation approach. We are therefore testing the mean state of the model using a few variables, sometimes focusing on some integrated indices over time or more extensively mapping the model-observation discrepancy in space and time.

In this contribution, we describe the model components and the verification strategy along with results of the evaluation of the latest hindcast. The objective is to present to the community the progress made and challenges met in developing a high-resolution modelling system for the ArcticAtlantic oceans in the spirit of Megann et al. (2014). In assessing the performance of the latest hindcast in terms of ice properties (concentration, thickness and velocity), we include comparison with an intermediate hindcast and the $1 / 12^{\circ}$ resolution equivalent global simulation ORCA12T321 of Mercator Océan.

More precisely, Sect. 2 is divided into the description of the model (domain, model components and parameters;

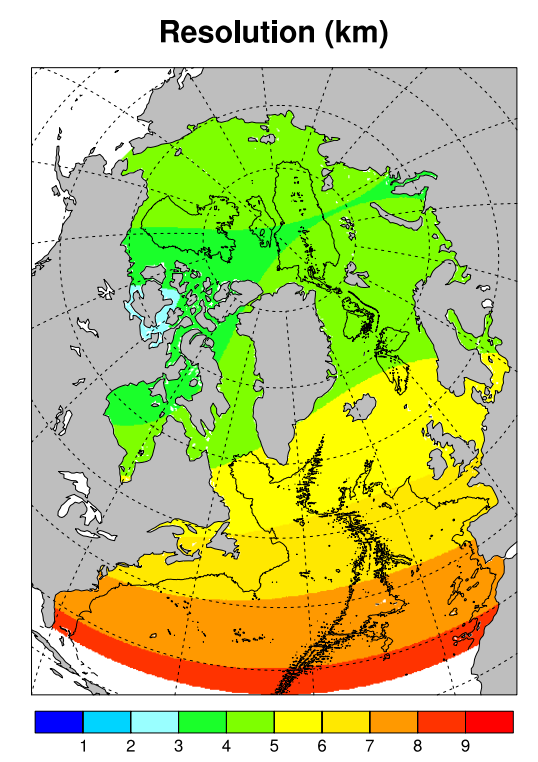

Figure 1. CREG12 domain and horizontal resolution (in kilometres). The $3000 \mathrm{~m}$ contour of the modelled bathymetry is overlaid.

Sect. 2.1), the input bathymetry and other initial and boundary conditions (Sect. 2.2) and the description of the verification package (Sect. 2.3). Section 3 provides details of the hindcast simulations (Sect. 3.1) and then describes the simulation results in terms of the statistics of the sea surface height, the hydrography and the general circulation (Sect. 3.2) and in terms of sea-ice metrics (concentration, thickness, volume and drift; Sect. 3.3). Section 4 concludes.

\section{Model setup, input data and verification package}

\subsection{Model description}

\subsubsection{Domain configuration}

The global ORCA12 domain (ORCA family grid at a nominal horizontal resolution of $1 / 12^{\circ}$ in both longitudinal and latitudinal directions; Drakkar Group, 2007) is used to derive a seamless (i.e., the "north-fold" discontinuity of the global grid is removed) regional domain covering the whole Arctic Ocean and parts of the North Atlantic down to $27^{\circ} \mathrm{N}$. The horizontal grid consists of $1580 \times 1817$ points on which resolution varies from $8 \mathrm{~km}$ at the open boundary in the Atlantic Ocean to an average of $5 \mathrm{~km}$ in the Arctic and down to slightly below $2 \mathrm{~km}$ in some of the southern channels of the Canadian Arctic Archipelago (Fig. 1).

The spatial variation of the first Rossby radius of deformation is shown in Fig. 2a. From about $40 \mathrm{~km}$ along the southern Atlantic boundary down to a few kilometres in the Labrador Sea, the Greenland, Iceland and Norwegian (GIN) seas and continental shelves, the radius increases again in the deep Arctic Ocean to above $10 \mathrm{~km}$. Relative to the local resolution 

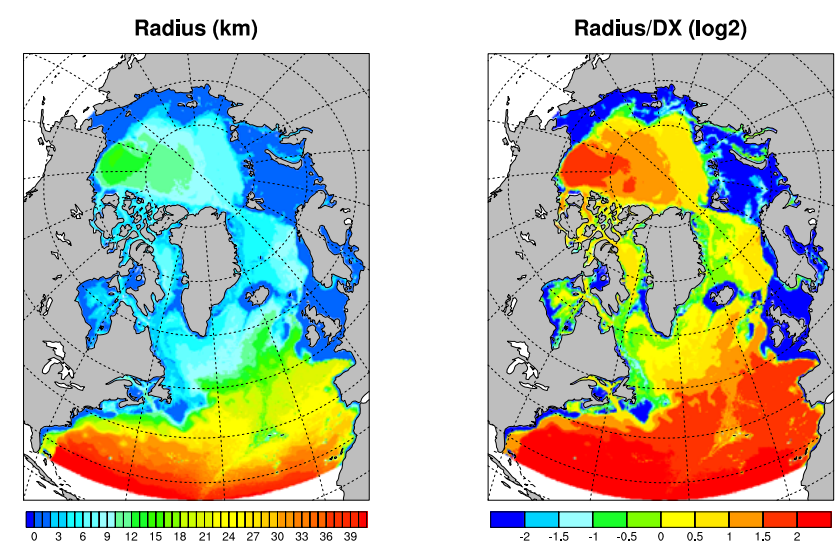

Figure 2. First Rossby radius of deformation (left, in kilometres) and Rossby radius relative to the local resolution in $\log 2$ (right). Grossly speaking, the right panel shows where model is eddy resolving (values above 1 , that is, 2 model points to resolve a baroclinic eddy), eddy permitting (between 0 and 1 ) or does not resolve eddies (values below 0 .)

(Fig. 2b), the model resolves - grossly speaking - baroclinic eddies in the Sargasso Sea and the Azores region, where there are at least two grid spacings for resolving the Rossby radius, but becomes eddy permitting in the Labrador Sea (one grid spacing) and less than permitting in the GIN seas (under one grid spacing). However, the model is again eddy resolving in the central Arctic Ocean, which is of importance for the present application.

\subsubsection{Ocean component}

The ocean component is taken from version 3.1 of NEMO with some code additions from Mercator Océan, the UK Met Office and the DRAKKAR community. NEMO is a biophysical ice-ocean multi-component system developed originally in Europe (Madec and NEMO team, 2008) that has evolved substantially since its introduction in the 2000s. The ocean engine of NEMO is the primitive equation model OPA (Océan Parallelisé; Madec et al., 1998) adapted to regional and global ocean circulation problems. NEMO is intended to be a flexible tool for studying the ocean and its interactions with the other components of Earth's climate system over a wide range of space- and timescales (Masson-Delmotte et al., 2006; Drillet et al., 2005; Barnier et al., 2006). An advantage of NEMO is its widespread use and continuous improvement by the scientific community (Rattan et al., 2010).

Previous versions of NEMO have been extensively tested and applied in Canada for global, basin and regional applications (Holloway and Wang, 2009; Zhu et al., 2009; Wang et al., 2010; Lu et al., 2014).

\subsubsection{Ocean model parameters}

We started from the configuration and parameters of the $1 / 12^{\circ}$ resolution equivalent global simulation, ORCA12T321 of Mercator Océan, which are described below, and notes will be made when departing. NEMO is run with the implicit free-surface solver and linear free surface (a version using a time-splitting approach and a non-linear free surface, including the simulation of the main constituents of the tides, is presently being evaluated). The present version uses the same 50 vertical $z$ levels used in GIOPS, with spacing increasing from $1 \mathrm{~m}$ at the surface to 450 at $5000 \mathrm{~m}$. Bottom partial steps are employed for an accurate representation of the varying bathymetry. The tracer advection uses the total variance diminishing scheme. The vectorial form for momentum is chosen, allowing conservation of both energy and enstrophy. The lateral diffusion operator is biharmonic for momentum along geopotential surfaces and harmonic for tracers along isopycnal surfaces. The biharmonic viscosity has a nominal value of $-1 \times 10^{10} \mathrm{~m}^{4} \mathrm{~s}^{-1}$ at the southernmost point and is scaled by the third power of the grid spacing over the rest of the computational domain. The harmonic diffusion coefficient for tracers follows the same resolutiondependence principle, with a nominal value of $50 \mathrm{~m}^{2} \mathrm{~s}^{-1}$ and a linear scaling. For momentum, we additionally tested the purely free-slip and no-slip lateral boundary dynamic conditions but retained the former one for most of the hindcasts. The background values for vertical viscosity and diffusivity are $10^{-4}$ and $10^{-5} \mathrm{~m}^{2} \mathrm{~s}^{-1}$, respectively. We have also experimented with the turbulent kinetic energy (TKE; Gaspar et al., 1990; Blanke and Delecluse, 1993) and generic length scale (GLS; Umlauf and Burchard, 2003) closure schemes. The bottom drag is quadratic with a fixed non-dimensional coefficient of $10^{-3}$. The model time step is $360 \mathrm{~s}$ for all hindcasts (including ORCA12-T321) except for hindcast H05, which required a decrease to $180 \mathrm{~s}$ after July 2007 to ensure stability close to Cambridge Bay (Canadian Arctic Archipelago).

\subsubsection{Sea-ice models}

Within NEMO3.1 the ocean is interfaced with the Louvainla-Neuve sea-ice model version 2 (LIM2, Fichefet and Maqueda, 1997) or version 3 (LIM3, not tested here; Vancoppenolle et al., 2009b, a). However, here we also use another community sea-ice model, CICE (described below).

LIM2 is a simple one-category ice model based on a Semtner three-layer thermodynamic model (two layers of ice and one layer of snow). A viscous-plastic (VP) constitutive law relates the internal ice stresses to the strain rates and the ice strength. It is based on an elliptical yield curve and a normal flow rule (Hibler, 1979). The VP solution is approached by iteration of a relaxation scheme to the implicit ice velocity problem. LIM2 was used for the first two hindcasts (details given below in Sect. 3.1 and Table 1) for sanity checks relative to the configuration used in ORCA12-T321. The lat- 
Table 1. Summary description of the different hindcasts produced to date. Dates are given in YYYYMMDD format.

\begin{tabular}{|c|c|c|c|c|c|}
\hline Experiment name & $\begin{array}{l}\text { Initial and } \\
\text { boundary } \\
\text { conditions }\end{array}$ & $\begin{array}{l}\text { Lateral } \\
\text { dyn. BC }\end{array}$ & $\begin{array}{l}\text { Ice } \\
\text { model }\end{array}$ & $\begin{array}{l}\text { Turbulence } \\
\text { scheme }\end{array}$ & Notes \\
\hline ORCA12-T321 & Levitus & free slip & LIM2 & TKE & $\begin{array}{l}\text { started } 19990101 \text { : air-ice drag of } 1.5 \times 10^{-3} \text {, ice-ocean } \\
\text { drag of } 1.0 \times 10^{-2}\end{array}$ \\
\hline H01 & GLORYS2v1 & no slip & LIM2 & TKE & $\begin{array}{l}\text { started 20020101: air-ice drag of } 1.63 \times 10^{-3} \text {, same ice- } \\
\text { ocean drag }\end{array}$ \\
\hline $\mathrm{H} 02$ & ORCA12-T321 & free slip & LIM2 & TKE & started 20030101 \\
\hline H03 & ORCA12-T321 & free slip & CICE & $k-\epsilon$ & $\begin{array}{l}\text { started } 20030101 \text {; reduced Bering flow to mean } 0.8 \mathrm{~Sv} \text {; } \\
\text { top ice roughness of } 5.0 \times 10^{-4} \mathrm{~m} \text {, ice-ocean drag of } \\
5.36 \times 10^{-3}\end{array}$ \\
\hline H04 & ORCA12-T321 & free slip & CICE & $k-\epsilon$ & $\begin{array}{l}\text { increased ice-ocean drag relative to } \mathrm{H} 03 \text { to } 2.32 \times 10^{-2} \text {, } \\
\text { corresponding to a bottom ice roughness of } 3.0 \times 10^{-2} \mathrm{~m}\end{array}$ \\
\hline H05 & ORCA12-T321 & free slip & CICE & $k-\epsilon$ & H04 with ice surface roughness as in CGRF $\left(1.0 \times 10^{-4} \mathrm{~m}\right)$ \\
\hline
\end{tabular}

ter actually used an upgraded dynamic solver based on the elastic-VP (EVP) approach (Hunke and Dukowicz, 1997, 2002; Bouillon et al., 2009) instead of the VP solver described above.

CICE (Hunke, 2001; Lipscomb et al., 2007; Hunke and Lipscomb, 2010) is a dynamic/thermodynamic sea-ice model, which can be used as a stand-alone model or coupled to an ocean model inside a climate modelling system. Herein, it is coupled to NEMO on the same grid as a single executable (Hewitt et al., 2011). CICE calculates the evolution of a thickness distribution. The thickness distribution evolves with both thermodynamic (vertical growth/melt, new ice formation and lateral melt) and dynamic processes (advection and redistribution).

The momentum equation is solved with the same EVP approach as described above for LIM2-EVP, although on a slightly different stencil (Arakawa C-grid in LIM2-EVP and B-grid for CICE). LIM2-VP is discretized over a B-grid stencil.

In both sea-ice models, the ice is supposed to be "levitating" (following the convention of Campin et al., 2008) over the ocean; that is, the growth or melt of ice does not impact the ocean volume and the presence of ice does not impact the position of the ocean surface. However, the ocean surface salinity needs to evolve appropriately during brine rejection or the flushing of meltwater. For this, a virtual salt flux approach is used, which converts the freshwater flux into a salinity flux to represent dilution or concentration of salt at fixed water volume.

\subsubsection{LIM2 and CICE parameters}

LIM2 solves the VP dynamics with prescribed ice-water and air-ice drag coefficients. The momentum stress is expressed using a simple quadratic law (McPhee, 1975) with a $0^{\circ}$ turning angle for both air and ocean in contact with ice. In the ORCA12-T321 run of Mercator Océan, the air- ice drag was reduced to $1.5 \times 10^{-3}$, whereas the default value of $1.63 \times 10^{-3}$ is used in our CREG12 LIM2 runs. The icewater drag is fixed to $1 \times 10^{-2}$ in all LIM2 runs (as in the Mercator Océan run). In ORCA12-T321, the ice module is called with a time step of $720 \mathrm{~s}$ (every two ocean model time steps); the EVP solver uses 400 sub-timesteps and a damping elastic time of $1350 \mathrm{~s}$. In the CREG12 LIM2 runs, the ice model is called every five ocean time steps (equivalent to an ice time step of $1800 \mathrm{~s}$ ). The VP solver performs 20 outer loops (the default is two) with a linear residual at convergence of $1 \times 10^{-6}$ or a maximum of 550 iterations. It should be noted here that NEMO-LIM2 users can tune the total ice extent and volume by adjusting the parameter hiccrit (Wang et al., 2010), a characteristic thickness that is used to determine changes in open water area during ice growth. Nonetheless, overestimation of the total ice extent or volume is often reported in NEMO-related publications (Massonnet et al., 2011; Blockley et al., 2014), likely related to the use of a too-large value of the aforementioned parameter for given configuration and forcing. ORCA12-T321 used hiccrit $=0.6 \mathrm{~m}$ and the same value is applied in the CREG12 LIM2 runs.

In CICE, both air-ice and ice-ocean stresses are also expressed using a simple quadratic law with a $0^{\circ}$ turning angle. Following Roy et al. (2015) for our last two hindcasts and because our first ocean layer thickness is relatively small, the ice-ocean drag coefficient is computed by a log-layer assumption using the oceanic first layer thickness and a roughness length scale of $0.03 \mathrm{~m}$ as suggested by Maykut and McPhee (1995) which yields a drag coefficient of $2.32 \times 10^{-2}$. The air-ice stress involves a more sophisticated formulation that takes into account the stability of the atmospheric boundary layer. Following again Roy et al. (2015), the roughness length scale for ice surface is set in our latest run to the value used in the Canadian GDPS reforecasts (CGRF; Smith et al., 2014) for consistency between the air-ice stress computed in CGRF and in CICE. These modi- 
fications can be seen as a more objective way of deriving the drag coefficients, as they are not retrieved from a calibration exercise.

Ten thickness categories are defined in CICE (as in Smith et al., 2015), with specific representation of both thin ice and thick ridged ice. CICE is called at every ocean time step. The remapping advection scheme is used and the EVP solver is run with 920 sub-time-steps. The ice strength is computed using the more physically realistic approach of Rothrock (1975). Based on studies with CICE run offline (Lemieux et al., 2015a), we increase the value of the newly formed ice in CICE (hfrazilmin) from 5 to $8 \mathrm{~cm}$. Otherwise, the default parameters and parametrizations of CICE thermodynamics were used with no further tuning. The number of layers is set to the default value (four ice layers and one for the snow). The default Community Climate System Model 3.0 scheme (CCSM3; Vertenstein et al., 2004) is used to calculate the albedo and the attenuation of the absorbed shortwave radiation. The sea-ice is assumed to have a salinity of $3.2 \mathrm{~g} \mathrm{~kg}^{-1}$. Lateral melting depends on a specified value of the average diameter of the ice floes (Steele, 1992), which is kept to the default value of $300 \mathrm{~m}$.

\subsection{Model input data}

\subsubsection{Atmospheric forcing}

The model is forced at the surface using the CGRF product (Smith et al., 2014) from 2002 (2003 for some other runs) to 2009. This product consists of a series of reforecasts using available historical operational analyses from the Canadian Meteorological Centre of Environment Canada. As such, it is not a true reanalysis as other centres produce. However, because it uses the global Canadian Numerical Weather Prediction (NWP) model (last updated in 2011), it provides a consistent set of global forecasts at higher resolution (nominally $33 \mathrm{~km}$ at $60^{\circ} \mathrm{N}$ ) than typical reanalyses. The only source of variation in the quality of the reforecasts is the quality of the initial state (the analysis), which varies during the historical period with the assimilation method and volume of observations used (more details can be found in Bélair et al., 2009). The resolution offered by this product allows for better resolution of mesoscale atmospheric features. The short- and long-wave radiation fields, however, require some level of correction as the NWP model is unable to simulate the marine clouds with sufficient accuracy. A climatological correction based not only on the month of interest but also on the forecast hour is derived from the GEWEX (https://eosweb.larc.nasa.gov/project/srb/srb_table) radiation product.

The frequency of the forcing fields is set to $3 \mathrm{~h}$, using hours 6-27 of each CGRF initiated at 00:00 UTC. CGRF is provided on $10 \mathrm{~m}$ wind and $2 \mathrm{~m}$ thermodynamic levels. Those are not true "prognostic" model levels but since conventions and model output dissemination require these levels, a "diag- nostic" procedure is used to derive quantities there. The first prognostic level for wind and temperature in CGRF is in fact approximately at $40 \mathrm{~m}$, and quantities at this level are also available and are thought to be less dependent on assimilated surface conditions and approximations made during the diagnostic procedure. We have therefore used the product at this level as input to the CORE air-sea exchange bulk formulae and the equivalent in CICE. The only limitation to this approach is LIM2, in which input atmospheric conditions are assumed at $10 \mathrm{~m}$ with pre-set constant neutral coefficients, causing an overestimation of wind stress by approximately 20 to $50 \%$ (the same overestimation problem likely affects the calculation of turbulent heat exchanges.)

\subsubsection{Bathymetry, initial and lateral boundary conditions}

The bathymetry used in the CREG12 configuration is taken from that used in the ORCA12-T321 run of Mercator Océan. It is based on ETOPO2 (http://www.ngdc.noaa.gov/mgg/ global, Amante and Eakins, 2009). The minimum depth is set at $20 \mathrm{~m}$.

Two sets of initial ocean conditions (comprising 3-D velocities, temperature, salinity and sea surface height) have been used. Firstly a reanalysis product, GLORYS2v1 (Ferry et al., 2012), is used. This covers the satellite altimetry and ARGO period (1993-2010), with assimilation of both of these data sets in the reanalysis as well as other in situ data. However, we found that, although the assimilation of observations leads to a remarkable agreement with observations at lower latitudes, GLORYS2v1 suffers from serious departures relative to observations and to the Polar Science Center Hydrographic Climatology (PHC, http://psc.apl.washington. edu/nonwp_projects/PHC/Climatology.html) in the Arctic. ${ }^{1}$ The second set of initial conditions used is simply derived from the ORCA12-T321 run of Mercator Océan, which has better hydrographic properties in the Arctic Ocean but is not as accurate as GLORYS2v1 at lower latitudes.

Sea-ice initial conditions are taken from the same initial condition product: either GLORYS2v1 or ORCA12-T321, both of which use the mono-category LIM2 model. The ice concentration and ice thickness of these products are applied to the corresponding ice category in CICE, while the other categories remain empty. It then takes several months of simulations before a realistic ice distribution can be recovered. An initial spread among several categories would therefore be more realistic. For snow, the ice category that receives the ice volume also receives the snow volume present in the initial conditions.

\footnotetext{
${ }^{1}$ Among other poor characteristics, the doming of sea surface height in the Beaufort Sea is absent and the Atlantic layer apparently spreads anti-cyclonically instead of cyclonically. This is in apparent contrast to studies done using GLORYS1 that were more successful, such as in Lique et al. (2011)
} 
Along the lateral open boundaries, time-evolving monthly conditions (comprising 3-D velocities, temperature and salinity (TS) from 2002 to 2009) are taken from the same products as the initial conditions. More specifically, a clamped velocity condition is specified (hence lateral transport) and a radiation scheme following the advective characteristic is applied for temperature and salinity combined with restoring to input values. The restoring time is 15 days when radiating outward and 1 day when inward. A closed wall boundary condition is applied to sea ice in LIM2 and CICE.

The river freshwater discharge was taken as in T321 from the monthly climatology of Dai and Trenberth (2002). No attempt was made in these hindcasts to investigate the impact of the interannual variation of Arctic river or glacial discharge; this was left to a future study.

\subsection{Verification package}

Evaluation of the system is performed by comparing model outputs with ocean observations. Additionally, the model outputs are compared with other model estimates and with climatologies. During the development phase, with the model running in hindcast mode, this evaluation provides an assessment of the improvements introduced with each change to the model configuration. Once the forecast system is operational, the verification package will provide an assessment of forecast accuracy.

The CONCEPTS evaluation strategy defines a set of model output fields, a database of ocean observations from both in situ and remote sensing measurements and a suite of metrics for comparing the two. This approach has been designed for the CREG12 configuration but was developed in such a way that it can easily be transferred to other CONCEPTS systems. The key model outputs for evaluation are sea surface height, ocean temperature, salinity and velocity, and sea-ice thickness, concentration and velocity. Additional derived output fields include transports through sections, freshwater content and mixed layer depth. The observation database incorporates measurements included in existing global databases combined with data from individual observation missions. These include missions using new technologies developed to provide measurements in the ice-covered regions of the Arctic. The ocean observation database includes traditional ship-deployed and moored in situ measurements of temperature, salinity and velocity, together with measurements from ARGO drifting profilers, ice-tethered profilers, gliders, mammal-mounted instruments and satellite remote sensing. The sea-ice observations include thickness and drift measurements from ice mass balance buoys and upward-looking sonar (ULS) together with remote sensing from aircraft- and satellite-mounted instruments.

\section{Model simulations and evaluation}

\subsection{Simulations}

Five hindcast simulations, $\mathrm{H} 01$ to $\mathrm{H} 05$, are carried out covering the years 2003 to 2009 , and these are briefly described in Table 1. LIM2 is used in H01 and H02 and CICE in H03 and higher. H01 is initialized from GLORYS2v1, which is found less reliable than ORCA12-T321 in the Arctic Ocean, our focus region. Hence $\mathrm{H} 02$ and higher are started instead from ORCA12-T321. Changes related to air-ice and ice-ocean drags based on Roy et al. (2015) were incrementally implemented in $\mathrm{H} 03$ to H05. Parameters are defined in Sect. 2.1.5. Hence H02 uses for instance a lower ice-ocean drag coefficient relative to H05 (approximately half). The treatment of the air-ice stress is also noteworthily different in $\mathrm{H02}$ as explained in Sect. 2.2.1, and therefore the magnitude of the stress is overestimated relative to H05. For the interest of the reader, we also note that the latest hindcast $\mathrm{H} 05$ has been used in a study of the role of eddy-induced transport of heat and buoyancy in the Labrador Sea (Saenko et al., 2014).

\subsection{Hydrography and circulation evaluation}

The focus of the evaluation is the most-recent model run, H05, but there are some brief comparisons with the earlier $\mathrm{H} 02$, which incorporates the LIM2 ice model rather than the CICE model. In this sense and in spite of other differences, $\mathrm{H} 02$ is the closest simulation to the ORCA12-T321 run. Most of the comparisons presented here are for the mean fields for the period 2003-2009 with additional discussions on time variability.

\subsubsection{Sea surface height (SSH)}

Satellite altimeters provide a continuous record of SSH anomalies since 1993 (Benveniste, 2011), with accuracy at the centimetre level. Figure 3 shows the mean (top), standard deviation (middle) and skewness (bottom) of SSH for the North Atlantic for the period 2003-2009 from the model hindcast H05 (left panels) and from the satellite record. The altimeter estimates of the standard deviation and skewness are produced using the gridded $1 / 4^{\circ}$ SSH AVISO anomaly product distributed by Archiving, Validation and Interpretation of Satellite Oceanographic data (AVISO, http://www.aviso.oceanobs.com/en/ data/products/auxiliary-products/mss/index.html). The mean altimeter SSH is the sum of the 2003-2009 SSH anomalies and the CNES-CLS09 mean dynamic topography (MDT, Rio et al., 2011).

The mean SSH fields from the model and altimeter record are very similar. The sharp gradient of the Gulf Stream can be seen in both, leaving the coast of North America around $35^{\circ} \mathrm{N}$ and following a similar path eastwards. The high SSH of the subtropical gyre can be seen to the south of the Gulf Stream and the low SSH of the subpolar gyre to the north. 

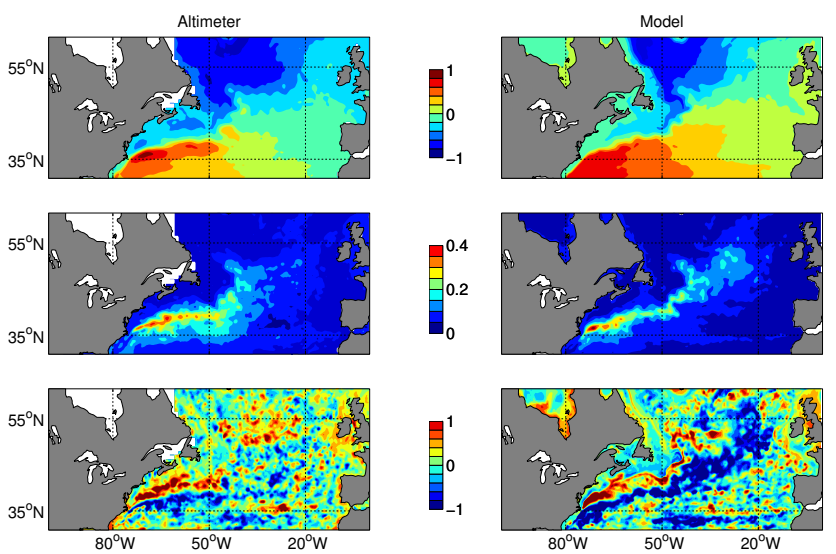

Figure 3. The mean (top), standard deviation (middle) and skewness (bottom) of sea surface height (in metres) in the North Atlantic from satellite altimeter measurements (left) and the model hindcast H05 (right) for the period 2003-2009.

The model estimate shows some sharper gradients, for example along the Labrador coast, but this is likely because of the higher horizontal resolution of the model $\left(1 / 12^{\circ}\right)$ compared to the resolution of the altimeter product $\left(1 / 4^{\circ}\right)$.

The spatial distribution of the magnitude of SSH variability, represented by the standard deviation plots, shows good agreement between the model and the altimeter measurements. The altimeter data show in general, however, a broader structure of medium values of standard deviation to the south of Gulf Stream, whereas the model shows medium values extending along the path of the North Atlantic current.

Positive and negative skewness corresponds to the meandering of a free jet such as the Gulf Stream or the variability caused by warm- and cold-core eddies (Thompson and Demirov, 2006). Typically, the zero contour of skewness separating strong regions of negative and positive skewness is a good indicator of the centre position of the mean currents. There is again good agreement between the model and the altimeter record in terms of the distribution of skewness for the Gulf Stream area, with the zero contour of the model being positioned slightly more to the north. A broad region of negative skewness in the model is also clearly visible in the mid- to eastern Atlantic Ocean which is not seen in the altimeter data. The interpretation of this is more difficult, except to note that the model must be producing more intense cyclonic than anticyclonic deviations in this region. Finally, the zero contour helps to define the position of the Azores current, which is well reproduced in the model in general but with perhaps a slightly more intense and narrower jet.

Most of the satellite altimeters that contribute to the AVISO record are unable to produce useful estimates of SSH in the Arctic, either because their orbits do not extend far enough north or because sea ice prevents the altimeter signal reaching the sea surface. However, Farrell et al. (2012) used measurements from the ICESat and Envisat satellite missions

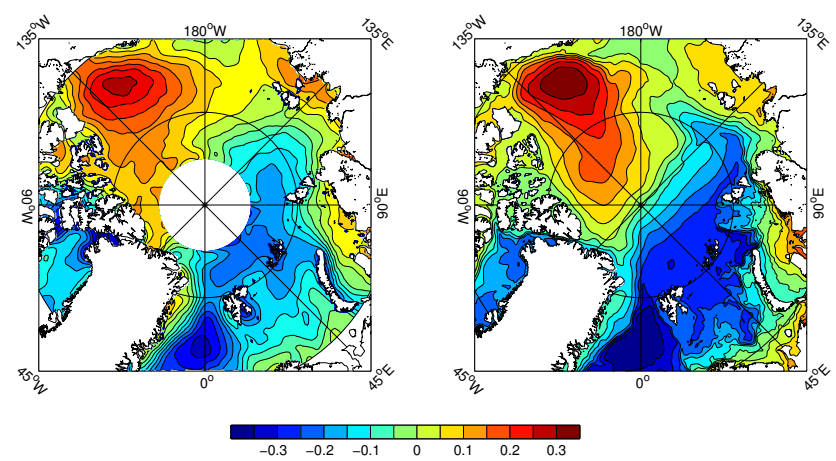

Figure 4. (Left) The estimated Arctic mean dynamic topography for the period 2003-2009, as described by Farrell et al. (2012). (Right) Modelled sea surface height (in metres) in the Arctic for the period 2003-2009 from hindcast H05.

to create an Arctic MDT for the period from 2003 to 2009, corresponding to the period of the hindcast. This resolves the large (basin)-scale features of the MDT, although it is unable to resolve small-scale features. Figure 4 shows the mean Arctic SSH from H05 and the MDT of Farrell et al. (2012). There is good agreement between the two estimates, both in terms of the patterns of SSH and the SSH gradients. For example, H05 shows a cross-Arctic sea level difference, from the high of the Beaufort Gyre to the low north of Spitzbergen, of approximately $60 \mathrm{~cm}$ compared to a difference of about $65 \mathrm{~cm}$ in the MDT of Farrell et al. (2012). Kwok and Morison (2011) similarly use ICESat data (winter only) to estimate the MDT of the Arctic, including its variability. The interannual variability of mean SSH in H05 (not shown here) compares well with their estimates, particularly in the Canada Basin.

\subsubsection{Surface circulation}

Figure 5 compares the mean current speeds from hindcast H05 to a $1 / 2^{\circ}$ resolution climatology derived from nearsurface drifter velocity estimates (Lumpkin and Johnson, 2013). The model speeds at $15 \mathrm{~m}$ depth (corresponding to the depth of the drifter drogues) were averaged for the period 2003-2009 and regridded at the same $1 / 2^{\circ}$ resolution as the climatology. The drifter estimates typically have an estimated error less than $3 \mathrm{~cm} \mathrm{~s}^{-1}$ in the deep North Atlantic. The general agreement between the model and drifter climatology is good; for example, the estimates of the speed and the position of the Gulf Stream and the North Atlantic current appear similar. On the north flank of the Gulf Stream, a weak but persistent branching is clearly visible in both plots, east of $70^{\circ} \mathrm{W}$, although that of the model detaches from and rejoins the Gulf Stream a little too early. This secondary current system is likely related to the slope water current described in Pickart et al. (1999) and Dupont et al. (2006). The East and West Greenland currents and the Labrador current contain more details in the model than can be captured by the drifter resolution, but the separation of coastal and shelf 

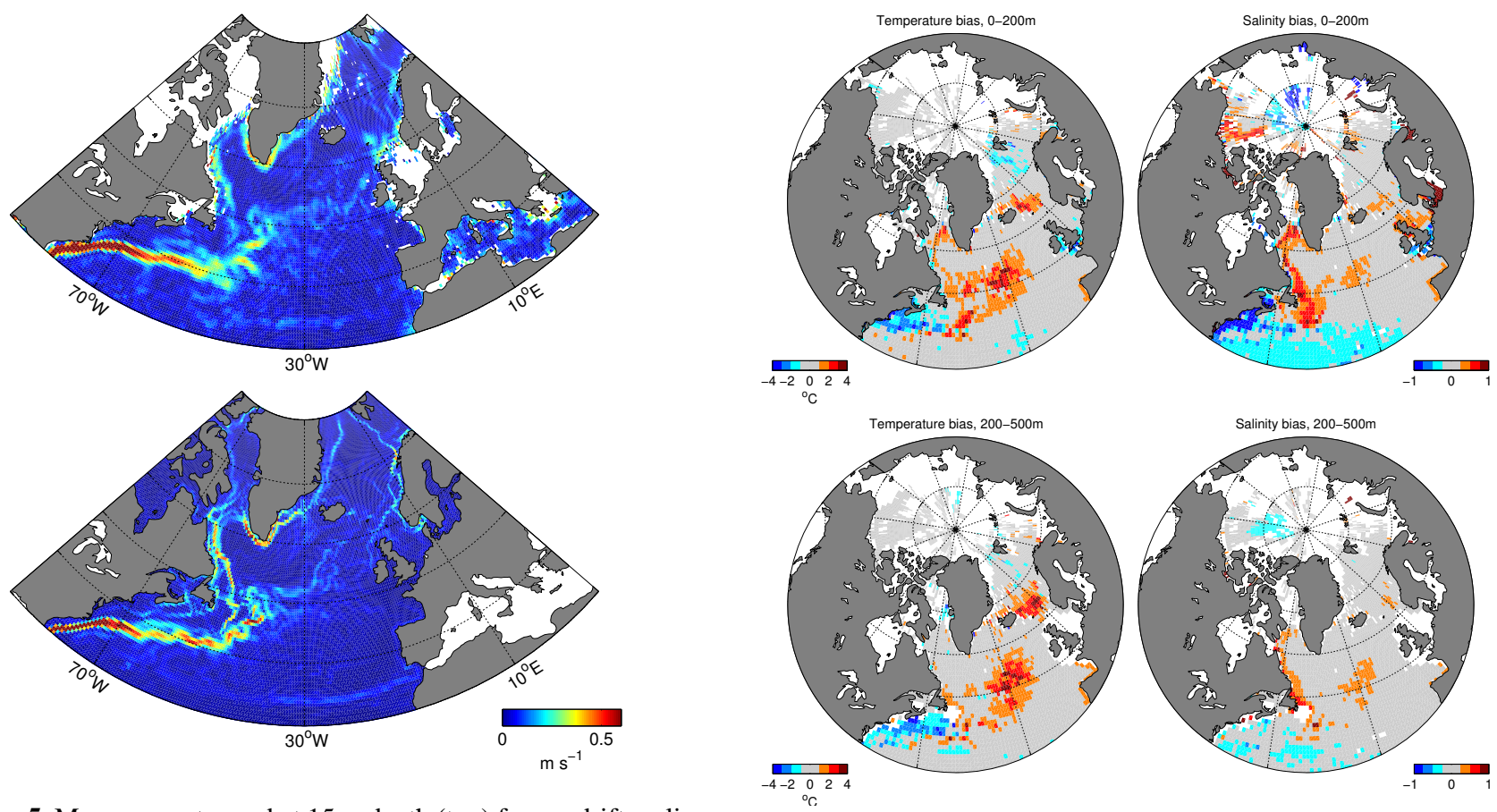

Figure 5. Mean current speed at $15 \mathrm{~m}$ depth (top) from a drifter climatology and (bottom) from hindcast $\mathrm{H} 05$ averaged for the period 2003-2009. The model output has been regridded to the same $1 / 2^{\circ}$ resolution as the drifter climatology.

jets is in good agreement with other observations (e.g., Higginson et al., 2011). Again, the path of the Azores current is visible in both model and observations.

\subsubsection{Temperature and salinity}

Quality-controlled measurements of ocean TS are available from the global CORA3.4 database distributed by MyOcean (www.myocean.eu). This database includes measurements from ship-based surveys, moorings and the drifting profilers of the ARGO network. In the Arctic there are relatively few observations compared with other ocean basins. Whilst some Arctic observation programmes have been incorporated into the CORA3.4 database, others are not yet included. We have undertaken a search of data available from all programmes and combined them with the CORA3.4 observations where they are missing. These observation programmes include the Beaufort Gyre Exploration Project (BGEP, http://www.whoi.edu/page.do?pid= 66296), the Ice-Tethered Profiler project (ITP, http://www. whoi.edu/page.do?pid=20756), the Canadian Basin Observational System (CABOS, http://nabos.iarc.uaf.edu/index. php), the Switchyard project (http://psc.apl.washington. edu/switchyard/overview.html), the North Pole Environmental Observatory (NPEO, http://psc.apl.washington.edu/ northpole/) and monitoring programmes in Davis Strait (e.g., Curry et al., 2013), Barrow Strait (e.g., Hamilton et al., 2013) and Fram Strait (e.g., Schauer et al., 2008).

Figure 6. The mean model bias for temperature (left) and salinity (right), calculated as the model hindcast H05 estimate minus the observed value, averaged in $1^{\circ}$ bins for the top $200 \mathrm{~m}$ (top) and the 200-500 m layer (bottom) for the period 2003-2009.

Figure 6 shows the mean TS bias for hindcast $\mathrm{H} 05$ for the period 2003-2009. Model values are extracted at the same time and location as observations, and the bias is calculated as the model estimate minus the observation. The biases are averaged in $1^{\circ}$ bins for the top $200 \mathrm{~m}$ and between 200 and $500 \mathrm{~m}$ depth. These intervals are chosen to quantify the nearsurface (including shelf) and intermediate depth anomalies. Measurement errors are negligible (typically $\pm 0.01{ }^{\circ} \mathrm{C}$ for temperature and \pm 0.01 for salinity; e.g., Talley et al., 2011). However, the model output is grid-cell averaged whereas the observations are point measurements that will be subject to additional variability. Accordingly, we consider averaged biases rather than comparisons with individual measurements.

Over large areas of both the North Atlantic and the Arctic oceans the average temperature biases are less than $\pm 1{ }^{\circ} \mathrm{C}$ and the salinity biases are less than \pm 0.5 . However, a warm and salty bias is seen in the central North Atlantic and in the currents that form the subpolar gyre. This bias is strongest in the surface layers, averaging more than $2^{\circ} \mathrm{C}$ (temperature) and 0.75 (salinity) in some places, and extends into the Iceland and Norwegian seas. The temperature bias extends along the path of the Gulf Stream, particularly in the surface layers. A cold bias also extends from the north side of the Gulf Stream toward the coast of the USA and Canada. The salinity bias is largest in the Labrador current. A salty bias is seen in the upper layers of the Beaufort Sea, extending along the coast of Canada toward Fram Strait (see also 


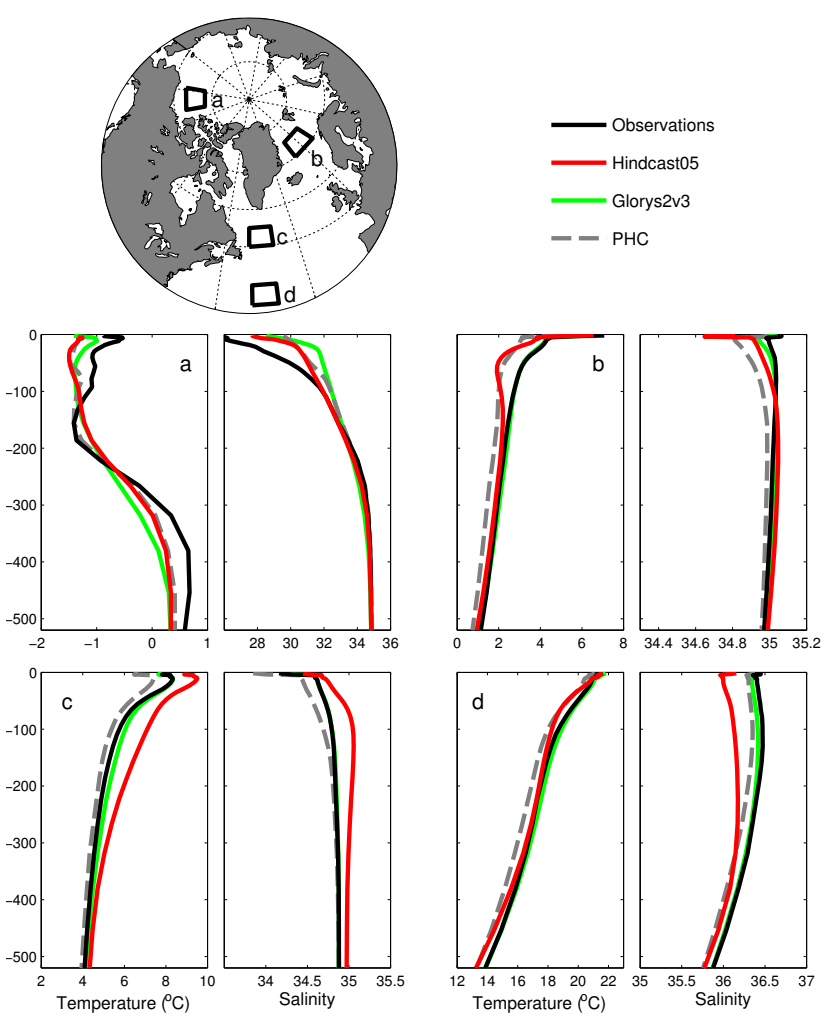

Figure 7. Average temperature and salinity profiles within the boxes shown in the top panel. All available observations within each box during the period 2003-2009 are averaged and plotted. Corresponding profiles from hindcast H05, the GLORYS2v3 ocean reanalysis and the Polar Science Center Hydrographic Climatology (PHC), calculated in each case by averaging profiles at the same times and locations as the observations, are also shown. The boxes represent (a) the Beaufort Sea $\left(73-78^{\circ} \mathrm{N}, 152-132^{\circ} \mathrm{W}\right)$, (b) the Greenland and Norwegian seas $\left(70-75^{\circ} \mathrm{N}, 10^{\circ} \mathrm{W}-10^{\circ} \mathrm{E}\right)$, (c) the subpolar gyre $\left(50-55^{\circ} \mathrm{N}, 50-40^{\circ} \mathrm{W}\right)$ and (d) the subtropical gyre (35$\left.40^{\circ} \mathrm{N}, 49-41^{\circ} \mathrm{W}\right)$. Note the different scaling on the horizontal axis for each panel.

Sect. 3.2.4). Conversely, the waters in the centre of the GIN seas are colder and somewhat fresher.

The vertical structure of the model TS compared to observations is shown in Fig. 7. Four domains were chosen to represent regions of oceanographic interest (the subtropical and subpolar gyres, the Beaufort Gyre and the Nordic seas). These domains (except for the subtropical gyre) correspond with regions of relatively high temperature or salinity averaged biases identified in Fig. 6. For each domain all available observations were averaged to give single temperature and salinity profiles. Model outputs at the same times and locations were extracted from hindcast H05, the GLORYS2v3 reanalysis product (Ferry et al., 2012) and the Polar Science Center Hydrographic Climatology (PHC). These were similarly averaged across each domain to give single temperature and salinity profiles for each product in each domain.

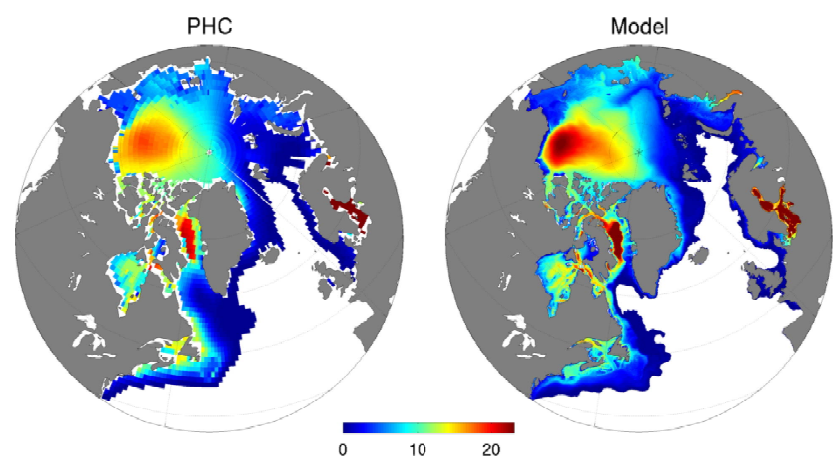

Figure 8. Mean liquid freshwater content (in metres) from the PHC climatology (left) and from hindcast H05 (right) for the period 2003-2009. The white regions of the ocean correspond to regions where salinity at any depth is above the 34.8 reference salinity used to compute the freshwater content.

The profiles for the subtropical gyre domain (Fig. 7d) show that the model does a good job of representing both temperature and salinity, although the top ocean layers are too fresh by 0.5 . In the subpolar gyre domain (Fig. 7c) the model bias in salinity is positive, with a maximum of less than 0.5 around $100 \mathrm{~m}$ depth. The warm bias has a maximum of around $2{ }^{\circ} \mathrm{C}$ at a similar depth. In the Greenland and Norwegian seas (Fig. 7b) there is a fresh and cold bias restricted to the top $100 \mathrm{~m}$ of the ocean. In the Beaufort Sea (Fig. 7a) the temperature biases are small (less than $0.5^{\circ} \mathrm{C}$ ), but the profile shows the bias to be cold in the Atlantic water layer (around $500 \mathrm{~m}$ depth) and near the surface and slightly warm in the Pacific water layer (around $150 \mathrm{~m}$ depth; Steele et al., 2004). The vertical temperature structure is not well reproduced by the model. This suggests that there may be problems with the transport and transformation of Pacific waters in the model, and this is an area for further investigation. We can only tell at this point that Pacific water signature weakens with time in $\mathrm{H} 05$ (not shown). A salty bias in the Beaufort Sea is restricted to the upper $75 \mathrm{~m}$ of the water column. Note that GLORYS2v3 and PHC are in good agreement for temperature but both depart noticeably from the observations in this area.

Examining the Beaufort Sea salinity bias in a little more detail, Fig. 8 shows the mean liquid freshwater content equivalent depth for the Arctic from H05 and from PHC. The freshwater content is calculated using the method described in Proshutinsky et al. (2009), with a reference salinity of 34.8. There is good agreement in terms of the distribution of liquid freshwater, with the greatest concentration in the Beaufort Gyre, but the total modelled freshwater content in the gyre is greater than in the climatology. This is likely because the PHC does not incorporate observations beyond 1998 and therefore does not reflect the recent increase in freshwater content estimated by Proshutinsky et al. (2009). In order to investigate whether this increase is reproduced in 


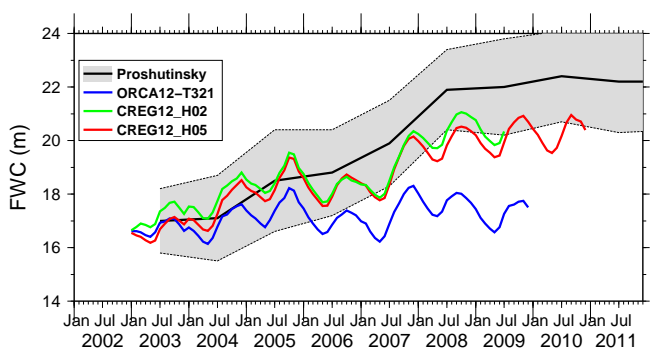

Figure 9. Time series of the estimated liquid freshwater content, averaged over the Beaufort Gyre, from Proshutinsky et al. (2009) and updates (black with uncertainties overlaid as grey area and bounded by dashed lines) compared with estimates from the ORCA12T321 run from Mercator Océan (blue) and CREG12 hindcasts H02 (green) and H05 (red).

the different simulations, we average the total monthly modelled liquid freshwater content over a pre-defined region of the Beaufort Gyre. We compare the modelled totals ( $\mathrm{H} 02$, H05 and ORCA12-T321) to the summer estimate (and uncertainties) over the same region based on observational data (Proshutinsky et al., 2009, and updates by A. Proshutinsky, personal communication, 2013) in Fig. 9. Because the modelled totals are plotted as monthly values, they exhibit a seasonal cycle that the observed estimate based on summer campaigns cannot reproduce. Based on the uncertainties provided with the summer estimate, we concluded that the observational error in total freshwater content is about $10 \%$. The two CREG12-based hindcasts reproduce fairly realistically the observed increase in freshwater content (although tapering by the end of the simulation period) whereas the ORCA12T321 content exhibits no such increase. We partly attribute this discrepancy to differences in atmospheric forcing products used in our hindcasts and ORCA12-T321. The fact that H05 shows a slightly poorer agreement with the observed freshwater estimates than $\mathrm{H} 02$ by the end of the simulation is due to the weaker Ekman pumping in the Beaufort Gyre, the latter explained by the smaller roughness and associated air-ice drag as described in Sect. 2.1.5 and Table 1. This will be illustrated from a different point of view in Sect. 3.3.2.

\subsubsection{Sections across Fram Strait and Davis Strait}

Arrays of moorings have been deployed across the main pathways for exchange of water between the Arctic and Atlantic, for example in Fram Strait (Schauer et al., 2008) and in Davis Strait (Curry et al., 2013). Figures 10 and 11 show a comparison of mean temperature, salinity and velocity estimated from these observations with corresponding estimates from hindcast H05 for Fram Strait and Davis Strait. The Fram Strait mooring observations cover the period 2005-2009 and the Davis Strait moorings cover 2004-2009, although not all instruments were deployed for the whole period. For each instrument all available observations are averaged. The output
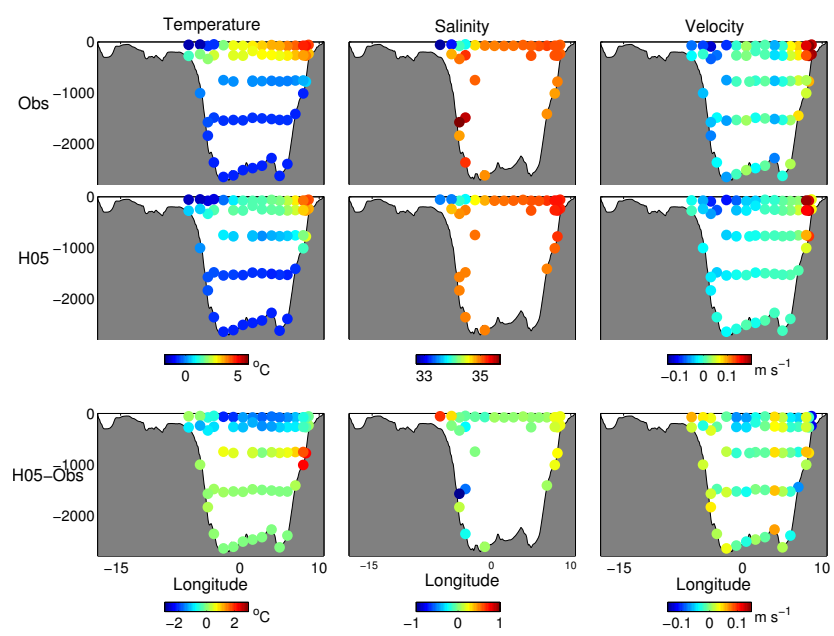

Figure 10. The mean observed (top), modelled (hindcast H05, middle) and difference (modelled minus observed, bottom) temperature (left), salinity (middle) and northward velocity (right) in Fram Strait.
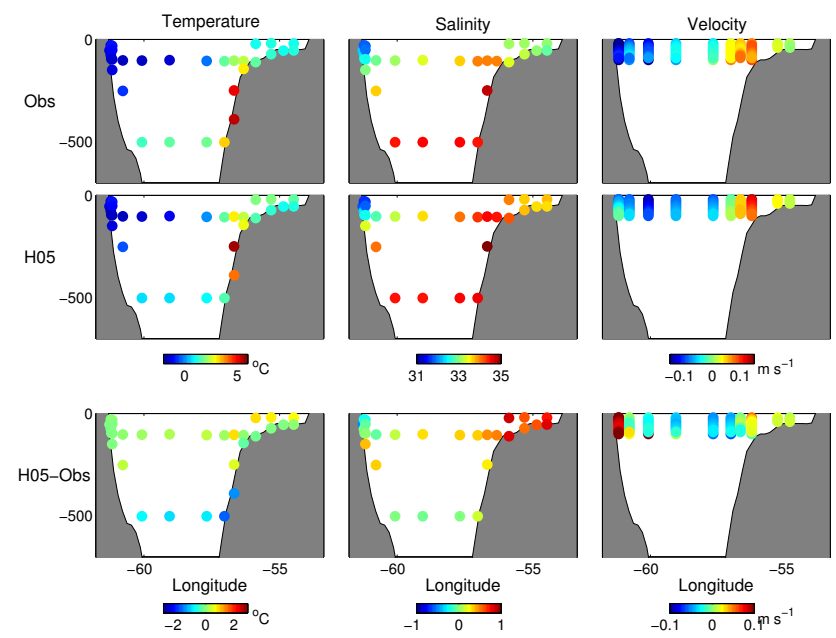

Figure 11. As for Fig. 10 but for Davis Strait.

from hindcast $\mathrm{H} 05$ is averaged for the corresponding times of each instrument. The contribution of measurement errors and mesoscale variability is negligible because of instrument calibration and averaging. However, sampling uncertainty may be an issue in the central sections of the straits where the moorings are spaced further apart, especially in Fram Strait where there is a recirculation within the Strait (Schauer et al., 2004).

Overall there is good agreement between the model and observations in Fram Strait. The large velocity of the northward-flowing West Spitzbergen current and the southward-flowing East Greenland current are very similar in magnitude and location. The temperature and salinity structures of the two currents are broadly similar, although the model shows a cold bias in the central channel and the mod- 


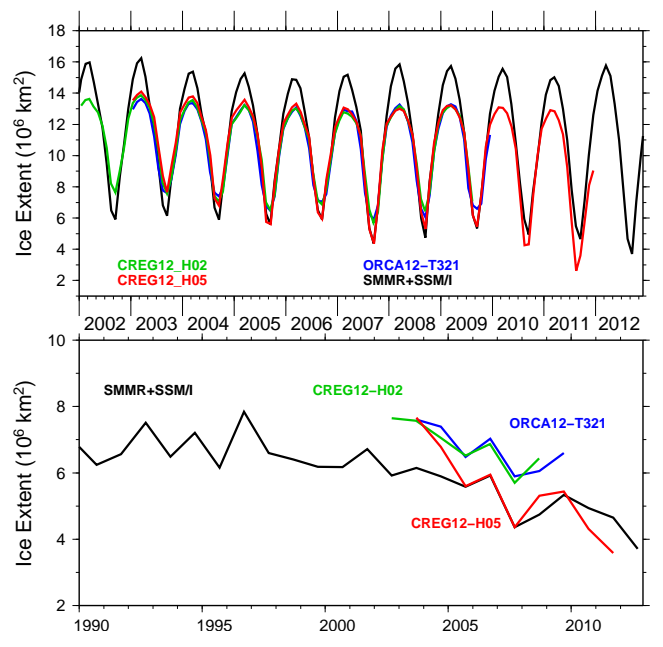

Figure 12. Monthly time series of total ice extent in the Arctic obtained from satellite observations (black, described as SMMR + SSM/I), the ORCA12 T321 run from Mercator Océan (blue) and CREG12 hindcasts H02 (green) and H05 (red). The top panel shows all months, while the bottom panel retains only September from each year.

elled northward-flowing water close to Spitzbergen is a little saltier than observed. The observations show a weaker northward-flowing branch of the West Spitzbergen current in the central channel, as described by Schauer et al. (2004), but this is absent in the simulation. This may explain the cold bias in the modelled near-surface waters in the centre of the strait.

In Davis Strait the observed and modelled temperatures are in good agreement. The salinity fields are also generally good, and the velocity maxima of the northward-flowing West Greenland current and the southward-flowing Baffin Island current (BIC) are similar in magnitude. However, the northward-flowing water on the Greenland shelf is a little too salty, likely related to the salty bias in the subpolar gyre described earlier, and the BIC is displaced further offshore in the model. There does not seem to be a strong temperature or salinity bias in the Arctic outflows through either Fram Strait or Davis Strait, suggesting that this is not the source of the biases seen in the Atlantic and discussed in the previous section.

The mean net liquid volume transport for 2003-2009 in hindcast H05 for Fram Strait is $2.7 \mathrm{~Sv}\left(1 \mathrm{~Sv}\right.$ is $\left.10^{6} \mathrm{~m}^{3} \mathrm{~s}^{-1}\right)$ toward the south compared to an observational estimate of $2 \pm 2.7 \mathrm{~Sv}$ (Schauer et al., 2008). For Davis Strait the model mean liquid volume transport is $1.9 \mathrm{~Sv}$ toward the south compared to an observed $1.6 \pm 0.5 \mathrm{~Sv}$ (Curry et al., 2013). The large observational uncertainties are generally associated with interpolation between mooring locations rather than measurement errors (see, for example, Fahrbach et al., 2001).

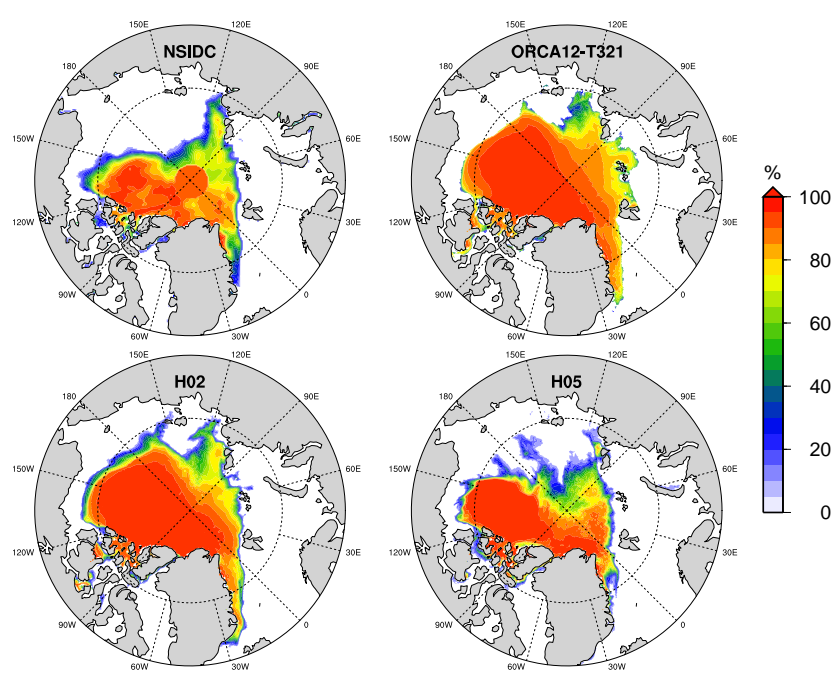

Figure 13. Ice concentration for September 2007 from NSIDC, the ORCA12 T321 run from Mercator Océan and CREG12 hindcasts $\mathrm{H} 02$ and $\mathrm{H} 05$.

\subsection{Sea-ice evaluation}

\subsubsection{Ice concentration, thickness and volume}

Estimates of the total ice extent (where ice concentration is higher than $15 \%$ ) have been derived from satellite products at the National Snow and Ice Data Center (NSIDC, Cavalieri et al., 1996, updated 2008), filling the North Pole data hole with $95 \%$ ice concentration. Ice extent is a more robust metric than ice area in summer as the latter is biased due to melt ponds detected as open water with errors on average around $10 \%$ (Comiso et al., 1997). Comparing H02 and H05, the implementation of CICE in H05 is beneficial in terms of better reproducing the seasonal cycle (Fig. 12, top panel). The ice thickness distribution allows for larger rates of melting and growth in the small ice thickness categories, thus enhancing the seasonal cycle of ice extent and bringing it closer to observations. Due to the missing North Pacific Ocean in the CREG12 domain, the maximum winter extent in the hindcasts does not reproduce the NSIDC estimate that covers all of the Northern Hemisphere (to ease comparison, ORCA12-T321 output is considered only on the CREG12 domain). In terms of the interannual variability of the September ice extent (Fig. 12, bottom panel), ice loss is faster in $\mathrm{H} 05$ than $\mathrm{H} 02$ during the first part of the simulation (2003-2005). This indicates an initial imbalance in thermodynamics, especially in H05, which takes close to 2 years to be resolved (see Sect. 2.2.2 for the initialization of CICE). After this, the total ice extent in $\mathrm{H} 05$ stays close to the observed estimate between 2005 and 2009. H05 September ice extent then starts to depart from observations after 2010 due to an anomalous accumulation of ice in the Beaufort Gyre and retreat elsewhere. H02 and T321 have a toolarge September ice extent but the negative trend is in general 


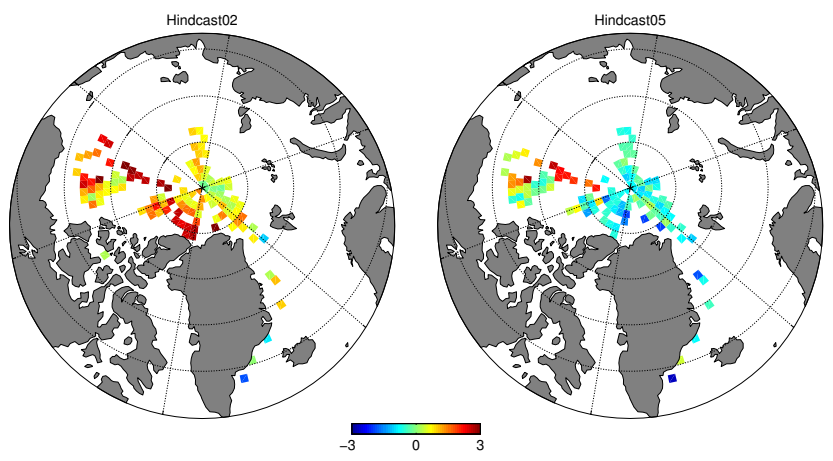

Figure 14. Difference (in metres, model minus observation) between the sea-ice thickness from hindcast H02 (left) and hindcast H05 (right) and measurements from ice mass balance buoys for the period 2003-2009 averaged across boxes measuring approximately $100 \mathrm{~km}$ square.

closer to observations than in H05, even though the period for comparison is too short to be statistically significant. This can be related to the fact that both H02 and ORCA12-T321 are in better thermodynamic balance with the initial condition, which itself is derived from a simulation using LIM2, than $\mathrm{H} 05$ which goes through a 2-year adjustment period. The 2007 minimum is well reproduced by $\mathrm{H} 05$ in terms of total ice extent, although the regional structure shows differences from the observations (Fig. 13). The ice concentration in Beaufort and Chukchi Seas is a little too high and that in the tongue of ice connecting the central pack along the Severnaya Zemlya archipelago to the mainland is somewhat too low. The ORCA12-T321 and H02 ice concentration fields are very similar in spatial structure, with T321 showing a sharper transition at the ice pack edge. They both overestimate the ice concentration in the Beaufort Sea and the East Siberian sector, which is in agreement with the total ice extent results.

In situ ice thickness observations are available from a number of different sources. Ice mass balance buoys (e.g., Polashenski et al., 2011) drift with the ice, measuring the evolution of the ice thickness with $\pm 0.01 \mathrm{~m}$ precision. For practical reasons, the deployments are generally in areas of multi-year ice. As we concentrate on the Central Arctic, this is less of a concern since the multi-year ice is the most representative type in this area. Sub-sampling is, however, still an issue and we therefore concentrate on the large structures. Figure 14 shows the mean difference between the model sea-ice thickness and the measured thickness. For each observation, the model thickness at the same time and location is obtained, and a bias is calculated. Biases are binned into boxes approximately $100 \mathrm{~km}$ square and averaged. H05, which uses the CICE ice model, clearly produces a result closer to observations than $\mathrm{H} 02$, which uses LIM2, but the ice in the Beaufort Gyre is still too thick. ULSs have been deployed on a number of subsurface moorings, providing high-frequency measurements of
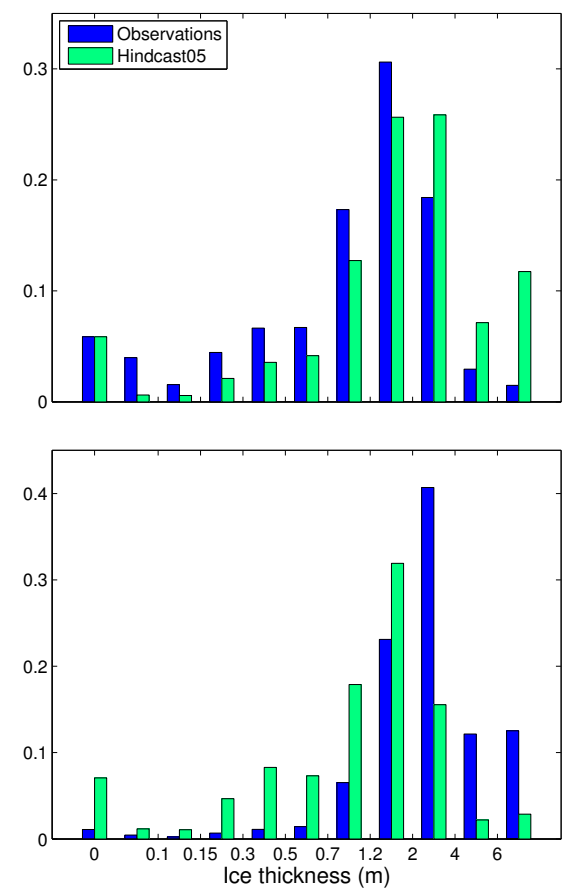

Figure 15. Average ice thickness distributions from ULS measurements (blue) and hindcast H05 (green) at the Beaufort Gyre Exploration Project (BGEP) mooring A (top) and at the North Pole Environmental Observatory mooring (bottom). The BGEP mooring data were averaged for the period September 2003 to December 2009. The NPEO mooring data were for the period January 2003 to December 2009 (but there are some gaps in the record). In each case the model output is averaged for the same period as the observations.

the ice draft from beneath. These data can be used to produce an estimate of the thickness distribution at the mooring location with an accuracy of $\pm 0.1 \mathrm{~m}$ (Kwok et al., 2004), which can be compared with the ice thickness distribution from the CICE model. Figure 15 compares the estimates from H05 with observations at one of the BGEP moorings (http://www.whoi.edu/beaufortgyre/data) and at the NPEO mooring (http://psc.apl.washington.edu/northpole/, Morison et al., 2002). The BGEP mooring data were averaged for the period September 2003 to December 2009. The NPEO mooring data were for the period January 2003 to December 2009 (but there are some gaps in the record). In each case the model output is averaged for the same period as the observations. The model reproduces the thickness distribution at both sites quite well, although it tends to overestimate the thicker ice categories in the Beaufort Gyre and underestimate them near the North Pole. Conversely, it can be noted that thinner categories are underestimated in the Beaufort Gyre but overestimated near the pole.

The spatial structure of the mean ice thickness (local total ice volume divided by total ice concentration) is also compared to estimates from the ICESat mission (Kwok et al., 


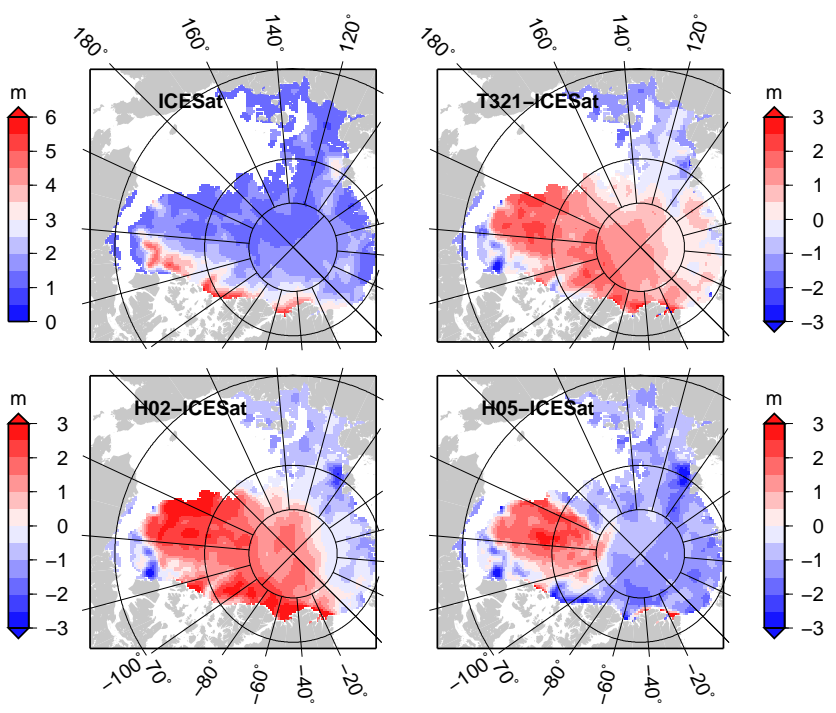

Figure 16. The mean ice thickness (in metres) for OctoberNovember 2007 from ICESat and the difference between ORCA12 T321 and CREG12 hindcasts H02 and H05 and the ICESat estimate.

2009) for the period October-November 2007. The uncertainty associated with the ICESat estimate can be as large as $0.5 \mathrm{~m}$. Thus, we only concentrate on the broad patterns. Figure 16 shows that ORCA12-T321 and H02 (both of which use LIM2) overestimate thickness over a large area. The mean ice thickness in H05 is closer to the ICESat observations, but there is a region of overestimated thickness in the Beaufort Gyre and an underestimation elsewhere which is consistent with our findings from the ice mass balance and ULS measurements and also with results of Roy et al. (2015).

Finally, the domain total ice volume of the different model simulations is compared to the estimate of the dataassimilative model PIOMAS (Zhang and Rothrock, 2003). This model ice volume compares well with estimates from ICESat and CryoSat2 (Laxon et al., 2013) and is therefore deemed a reasonable reference with a $10-15 \%$ uncertainty (based on their Fig. 3). The seasonal cycle (Fig. 17, top panel) for H05 is very close to the PIOMAS (although with a 1-month lag) and is a clear improvement over $\mathrm{H} 02$ and ORCA12-T321. The September values (Fig. 17, bottom panel) emphasize the discrepancy between the different hindcasts: $\mathrm{H} 05$ is close to PIOMAS in magnitude and trend, while ORCA12-T321 and H02 do not have a clear trend and the volume is overestimated by 50 to $100 \%$. This volume overestimation in ORCA12-T321 and H02 is consistent with the findings from in situ and satellite thickness measurements. Here, too, the different drag coefficients partially explained the convergence and accumulation of ice in the Beaufort Gyre. The higher ice-ocean drag and the lower air-ice drag in $\mathrm{H} 05$ both concur to reduce the ice velocity and therefore the Ekman convergence there relative to $\mathrm{H} 02$.

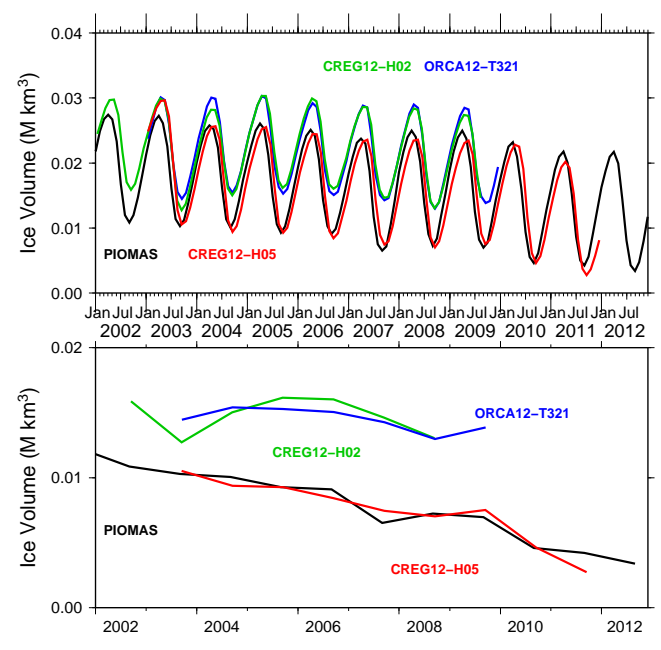

Figure 17. Monthly time series of total ice volume in the Arctic obtained from PIOMAS (black), the ORCA12 T321 run from Mercator Océan (blue), and CREG12 hindcasts H02 (green) and H05 (red). The top panel shows all months, while the bottom panel retains only September from each year.

The modification to the surface ice roughness between H04 and H05 has a positive impact, improving the absolute value and trend in the volume (not shown). However, although the total volume of $\mathrm{H} 05$ is very much on a par with estimates from PIOMAS, this conceals regional errors, such as an overestimation of ice thickness in the Beaufort Gyre, that were discussed earlier. The source of these errors in the Beaufort Gyre is likely related to the ice drift pattern, which is discussed in the following section.

\subsubsection{Ice velocity}

Satellite estimates of mean ice velocity, produced at $25 \mathrm{~km}$ resolution (Fowler et al., 2013), were obtained for March in the years 2003 to 2008 from NSIDC. These are averaged and compared to averages for the corresponding period from the same three hindcasts (ORCA12-T321, H02 and H05) in Fig. 18. The satellite and model estimates are coherent over large spatial scales $(500 \mathrm{~km})$, with a clearly defined Beaufort Gyre, Transpolar Drift and Fram Strait outflow. The estimates differ mainly in the intensity of the ice flow in the Beaufort Gyre and the Transpolar Drift. One can see the improvement from hindcast $\mathrm{H} 02$ to $\mathrm{H} 05$ as the ice-water and air-ice drags are adjusted following a semi-objective approach (Roy et al., 2015). However, the ice velocity in H05 is still too high compared to the satellite estimate. The ORCA12-T321 solution is the closest to the satellite estimate.

Given the similarity in ice circulation between the different products, a simple metric is now considered. The difference between the velocity calculated from the buoy displacements of the International Arctic Buoy Program (IABP; http://iabp.apl.washington.edu/) and from the model at cor- 


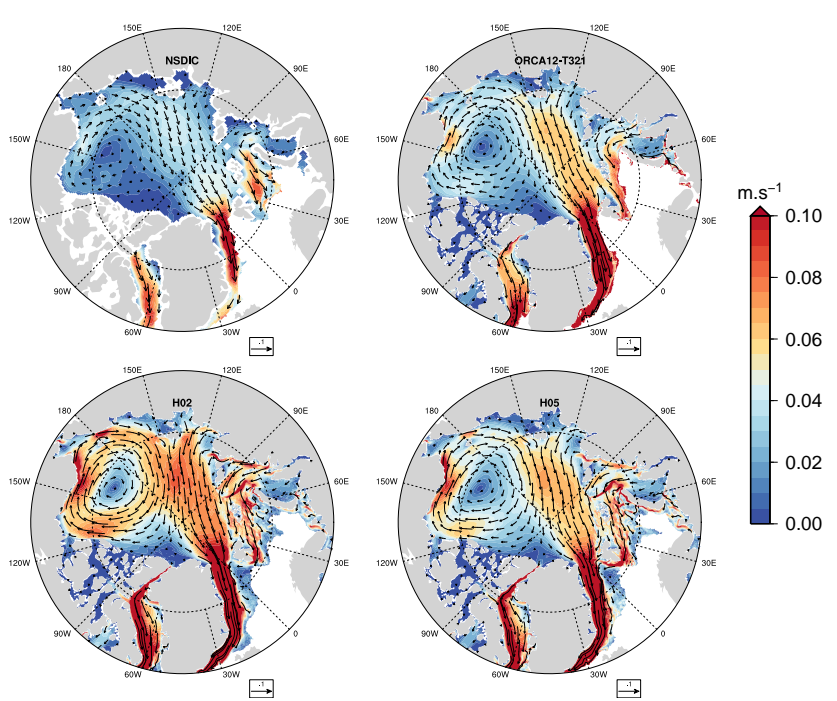

Figure 18. Average ice velocity (in $\mathrm{m} \mathrm{s}^{-1}$ ) for March 2003-2008 from NSIDC, the ORCA12 T321 run from Mercator Océan and CREG12 hindcasts H02 and H05.

responding times and locations is averaged for the period 2003-2009 (Fig. 19). The buoy locations are provided with an uncertainty of $\pm 100 \mathrm{~m}$ so, assuming a monthly averaged velocity of $0.05 \mathrm{~m} \mathrm{~s}^{-1}$, the uncertainty is much less than $1 \%$. The monthly ice velocity field is generally coherent over large scales, so the issue of irregular sampling by the buoys should not be too critical. Figure 19 shows that the satellite estimate is the closest to the buoy drifts (albeit with a slight negative bias), followed by ORCA12-T321, H05 and H02. The H05 bias is close to that of ORCA12-T321 but starts to deviate in late 2006. These results are consistent with those from the average March velocity maps in Fig. 18.

This evidence suggests that Ekman transport is still acting too strongly in $\mathrm{H} 05$, driving a convergence of ice and accumulation of multi-year ice in the Beaufort Gyre. An obvious reasoning is that the air-ice stress is too large (either due to too-strong winds or/and drag coefficient), driving the ice too fast. However, the CGRF surface winds tend to show a weak negative bias compared to observations at ice station Tara (not shown). This is in contrast to some reanalysis products compared by Jakobson et al. (2012) such as ERA-INT. Moreover, the surface ice roughness length scale in CGRF is actually smaller that the one used in ERA-INT. Hence the air-ice stress is less likely to be overestimated. However, the freshwater content increase during the period 2003-2009 in H05 is slightly weaker than observed (Fig. 9), which suggests the opposite, that is, the convergence of freshwater due to Ekman transport acting on the ocean may be underestimated. This issue needs to be further studied. Some mechanisms explaining variations in the Arctic freshwater content caused by dependencies on model parameters are also assessed in Roy et al. (2015). Preliminary results point to deficiencies in the vertical mixing scheme used in $\mathrm{H} 05(k-\epsilon)$ in the Arctic

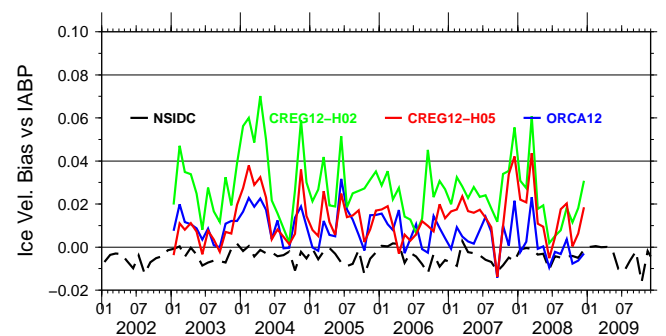

Figure 19. Monthly time series of average bias in monthly ice speed (in $\mathrm{m} \mathrm{s}^{-1}$ ) relative to IABP buoys for NSIDC (black dashed), the ORCA12 T321 run (blue) and CREG12 hindcasts H02 (green) and H05 (red).

upper ocean which would explain the overly strong ice velocity in the Beaufort Gyre by underestimating the shallow convection under the ice.

Additionally, we note that the lack of landfast ice parametrization may explain the overestimation of the ice velocity in all model runs in the East Siberian, Laptev and Kara Seas in Fig. 18.

\section{Conclusions}

The development of a high-resolution ice-ocean modelling system is a challenging task that requires a team effort. In CONCEPTS this is achieved by collaborations among different Canadian government departments and international collaborators such as Mercator Océan. The CREG12-based system consists of state-of-the-art ocean and sea-ice models, a comprehensive verification package and a data assimilation capability under development. Before proposing the system for operational implementation, the capability of the ice-ocean model to produce high-quality hindcasts must be demonstrated. Hence, the present approach of producing a series of hindcasts and identifying deficiencies helps in deciding which aspects of the system need to be improved. For instance, the upper ocean physics and more accurate initialization fields appear as areas of particular concern.

Each multi-year hindcast, driven by the high-resolution CGRF forcing, shows incremental improvements with changes to the initial and boundary conditions, the lateral friction schemes, turbulent mixing parametrizations and finally the change of sea-ice model from LIM2 to CICE. The verification package includes a variety of ocean and sea-ice observations. It demonstrates the capability of the model in hindcasting the mean, variance and skewness of the SSH, the position and strength of the surface circulation.

In terms of temperature-salinity distributions, the initial conditions (however accurate or poor they can be) still imprint the results after 8 years and therefore only variations in the upper ocean can be analyzed. From this point of view, the $k-\epsilon$ mixing scheme seems adequate in the north Atlantic but likely underestimates the shallow convection below the 
ice and this may explain the degradation of some of the upper ocean water masses of the Arctic Ocean such as the Pacific layer. Nonetheless, the freshwater content in the Beaufort Sea and its interannual variations are well reproduced by the model, including the seasonal and interannual variations of the Arctic sea-ice extent and total volume. The Fram Strait long-term averages were in general well reproduced by the model, with the exception that the model misses the offshore extension of the northward-flowing branch of the Spitzbergen current, which leads to a small but still important loss of Atlantic inflow into the Arctic. The Davis Strait results show that the model has a northward West Greenland current flowing a little too far north and a too-strong southward Baffin current, the net being too much Arctic southward flow, while the modelled structure is generally accurate.

The model reproduces the major patterns of sea-ice velocity but the intensity is too strong, especially in the Beaufort Gyre. This is correlated to too-thick ice in the Beaufort Sea (and too-thin ice over the pole) which points to an overestimated Ekman transport in the upper ocean but needs to be further investigated. Preliminary results suggest - again deficiencies of the $k-\epsilon$ mixing scheme during winter convection. The change from LIM2 to CICE was beneficial in terms of thermodynamics as the seasonal cycle of total ice extent and volume is more pronounced and closer to observations and qualified modelled estimates, but other differences between the two, such as the ice velocity intensity and ice convergence in the Beaufort Gyre, are related to differences in the drag coefficients. No effort was made for instance to improve LIM2 wind and oceanic stress over ice, contrary to Roy et al. (2015). We noted some obvious differences between H02 and T321. For instance, the freshwater content of the Beaufort Sea in T321 does not reproduce the observed increase whereas H02 does. However, T321 has a more reasonable pattern of ice thickness and its March ice velocity is the closest to observations. These differences could point to differences in atmospheric forcing, although we cannot exclude other model errors such as the noted overestimation of the air-ice stress in $\mathrm{H} 02$ (i.e., too-strong Ekman transport and pumping) and possibly too-strong vertical mixing in all configurations ${ }^{2}$.

Finally, different advances in ice modelling and ice-ocean coupling are of interest to this project. First, although not critical for the type of evaluation done here, there is a strong incentive (Hibler, 2001; Campin et al., 2008; Griffies et al., 2011) in moving to a more exact "embedded" sea-ice representation in the ocean water column (ice loading effect, volume exchange, true salt flux, implicit momentum coupling between ice and ocean) with possible impacts in shallow channels where ice pressure ridges could restrain the passage of water underneath. This will be tested in the upcoming future. Second, a landfast ice parametrization (Lemieux et al.,

\footnotetext{
${ }^{2}$ Note that the background diffusivity value used in our hindcasts is 10 -fold that recommended by Zhang and Steele (2007)
}

2015b) should improve the representation of ice dynamics over the shelves, especially on the Siberian side, and we are hopeful for results in the very near future in this area as well. Third, two-way coupling of the wave field, the ocean and the ice is in progress (Dumont et al., 2011) and is expected to improve substantially the upper ocean response (with the addition of Stokes currents and induced mixing), the representation of the ice in the marginal ice zone and the wave field in general.

Additionally, promising advances in the parametrization of form drag (Tsamados et al., 2014) of air-ice, sea-ice and rheology (Tsamados et al., 2013) need to be implemented and tested, although for the latter it is not clear how beneficial this new rheology can be at high resolution - which is true of any existing rheology for that matter. The two latter advances are already available in CICE5 (Turner and Hunke, 2015). We also plan to move to NEMO version 3.6 in the upcoming future, which will offer support for coupling to CICE5. Finally, we are hopeful that we can increase the vertical resolution of the ocean component to 75 levels with a limit to $250 \mathrm{~m}$ thick layers in the deep ocean instead of the present $450 \mathrm{~m}$ limit. This would put us on a par with DRAKKAR and Mercator Océan's latest standards used in research.

Acknowledgements. This research was made possible thanks to funding from METAREA and BREA. The Gewex data were obtained from the NASA Langley Research Center Atmospheric Science Data Center. The altimeter products were produced by Ssalto/Duacs and distributed by Aviso, with support from Cnes (http://www.aviso.altimetry.fr/duacs/). The reanalysis products (GLORYS) and the observational data CORA3.4 were accessed through MyOcean. The BGEP and ITP data were downloaded from Woods Hole Oceanographic Institute. We are grateful for NSIDC for providing ice concentration and velocity products, Sinead Farrell for the Arctic MDT and IABP for Arctic buoy data. Finally, the manuscript benefited from the insightful comments of Daniel Deacu and two anonymous reviewers.

Edited by: S. Valcke

\section{References}

Amante, C. and Eakins, B. W.: ETOPO1 1-Arc-Minute Global Relief Model: Procedures, Data Sources and Analysis, Tech. rep., NOAA Technical Memorandum NESDIS NGDC-24, National Geophysical Data Center, NOAA, doi:10.7289/V5C8276M, 2009.

Barnier, B., Madec, G., Penduff, T., Molines, J.-M., Tréguier, A.M., Sommer, J. L., Beckmann, A., Biastoch, A., Böning, C., Dengg, J., Derval, C., Durand, E., Gulev, S., Rémy, E., Talandier, C., Theetten, S., Maltrud, M. E., McClean, J., and Cuevas, B. D.: Impact of partial steps and momentum advection schemes in a global ocean circulation model at eddy permitting resolution, Ocean Dynam., 56, 543-567, doi:10.1007/s10236-006-0082-1, 2006. 
Bélair, S., Roch, M., Leduc, A.-M., Vaillancourt, P. A., Laroche, S., and Mailhot, J.: Medium-range quantitative precipitation forecasts from Canada's new 33-km deterministic global operational system, Weather Forecast., 24, 690-708, doi:10.1175/2008WAF2222175.1, 2009.

Benveniste, J.: Radar altimetry: past, present and future, in: Coastal Altimetry, edited by: Vignudelli, S., Kostianoy, A., Cipolline, P., and Benveniste, J., chap. 1, pp. 1-17, Springer-Verlag, doi:10.1007/978-3-642-12796-0_1, 2011.

Blanke, B. and Delecluse, P.: Variability of the tropical Atlantic Ocean simulated by a general circulation model with two different mixed-layer physics, J. Phys. Oceanogr., 23, 1363-1388, 1993.

Blockley, E. W., Martin, M. J., McLaren, A. J., Ryan, A. G., Waters, J., Lea, D. J., Mirouze, I., Peterson, K. A., Sellar, A., and Storkey, D.: Recent development of the Met Office operational ocean forecasting system: an overview and assessment of the new Global FOAM forecasts, Geosci. Model Dev., 7, 2613-2638, doi:10.5194/gmd-7-2613-2014, 2014.

Bouillon, S., Morales Maqueda, M. A., Legat, V., and Fichefet, T.: An elastic-viscous-plastic sea ice model formulated on Arakawa B and C grids, Ocean Model., 27, 174-184, doi:10.1016/j.ocemod.2009.01.004, 2009.

Campin, J.-M., Marshall, J., and Ferreira, D.: Sea ice-ocean coupling using a rescaled vertical coordinate $z^{*}$, Ocean Model., 24, 1-14, doi:10.1016/j.ocemod.2008.05.005, 2008.

Cavalieri, D. C., Parkinson, C., Gloersen, P., and Zwally, H. J.: Sea ice concentrations from NIMBUS-7 SMMR and DMSP SSM/I passive microwave data, [1979-2006], Tech. rep., National Snow and Ice Data Center, Boulder, Colorado USA, digital media, 1996, updated 2008.

Comiso, J. C., Cavalieri, D. J., Parkinson, C. L., and Gloersen, P.: Passive microwave algorithms for sea ice concentration: A comparison of two techniques, Remote Sens. Environ., 60, 357-384, 1997.

Curry, B., Lee, C., Petrie, B., Moritz, R., and Kwok, R.: Multi-year volume, liquid freshwater, and sea ice transports through Davis Strait, 2004-2010, J. Phys. Oceanogr., 12441266, doi:10.1175/JPO-D-13-0177.1, 2013.

Dai, A. and Trenberth, K. E.: Estimates of freshwater discharge from continents: Latitudinal and seasonal variations, J. Hydrometeorol., 3, 660-687, 2002.

Drakkar Group: Eddy permitting ocean circulation hindcasts of past decades, Clivar Exchanges, 12, 8-10, 2007.

Drillet, Y., Bourdallé-Badie, R., Siefridt, L., and Provost, C. L.: Meddies in the Mercator North Atlantic and Mediterranean Sea eddy-resolving model, J. Geophys. Res., 110, C03016, doi:10.1029/2003JC002170, 2005.

Dumont, D., Kohout, A., and Bertino, L.: A wave-based model for the marginal ice zone including a floe breaking parameterization, J. Geophys. Res., 116, C04001, doi:10.1029/2010JC006682, 2011.

Dupont, F., Hannah, C. G., and Wright, D. G.: Model investigation of the Slope Water, north of the Gulf Stream, Geophys. Res. Lett., 33, L05604, doi:10.1029/2005GL025321, 2006.

Dupont, F., Chittibabu, P., Fortin, V., Rao, Y. R., and Lu, Y.: Assessment of a NEMO-based hydrodynamic modelling system for the Great Lakes, Water Qual. Res. J. Can., 47, 198-214, doi:10.2166/wqrjc.2012.014, 2012.
Fahrbach, E., Meincke, J., Østerhus, S., Rohardt, G., Schauer, U., Tverberg, V., and Verduin, J.: Direct measurements of volume transports through Fram Strait, Polar Res., 20, 217-224, 2001.

Farrell, S. L., McAdoo, D. C., Laxon, S. W., Zwally, H. J., Yi, D., Ridout, A., and Giles, K.: Mean dynamic topography of the Arctic Ocean, Geophys. Res. Lett., 39, L01601, doi:10.1029/2011GL050052, 2012.

Ferry, N., Parent, L., Garric, G., Bricaud, C., Testut, C.-E., Galloudec, O. L., Lellouche, J.-M., Drevillon, M., Greiner, E., Barnier, B., Molines, J.-M., Jourdain, N. C., Guinehut, S., Cabanes, C., and Zawadzki, L.: GLORYS2V1 global ocean reanalysis of the altimetric era (1992-2009) at meso scale, Mercator Quarterly Newsletter, 44, 29-39, available at: http://www. mercator-ocean.fr/eng/actualites-agenda/newsletter, 2012.

Fichefet, T. and Maqueda, M. A. M.: Sensitivity of a global sea ice model to the treatment of ice thermodynamics and dynamics, J. Geophys. Res., 102, 12609-12646, doi:10.1029/97JC00480, 1997.

Fowler, C., Emery, W., and Tschudi, M.: Polar pathfinder daily $25 \mathrm{~km}$ EASE-grid sea ice motion vectors. Version 2 [20022009], Tech. rep., Boulder, Colorado USA: NASA DAAC at the National Snow and Ice Data Center, 2013.

Gaspar, P., Gregoris, Y., and Lefevre, J. M.: A simple eddy kinetic energy model for simulations of the oceanic vertical mixing: Tests at station Papa and long-term upper ocean study site, J. Geophys. Res., 95, 16179-16193, 1990.

Griffies, S. M., Winton, M., Donner, L. J., Horowitz, L. W., Downes, S. M., Farneti, R., Gnanadesikan, A., Hurlin, W. J., Lee, H.-C., Liang, Z., Palter, J. B., Samuels, B. L., Wittenberg, A. T., Wyman, B. L., Yin, J., and Zadeh, N.: The GFDL CM3 Coupled Climate Model: characteristics of the ocean and sea ice simulations, J. Climate, 24, 13520-13544, doi:10.1175/2011JCLI3964.1, 2011.

Hamilton, J. M., Collins, K., and Prinsenberg, S. J.: Links between ocean properties, ice cover, and plankton dynamics on interannual time scales in the Canadian Arctic Archipelago, J. Geophys. Res., 118, 5625-5639, doi:10.1002/jgrc.20382, 2013.

Hewitt, H. T., Copsey, D., Culverwell, I. D., Harris, C. M., Hill, R. S. R., Keen, A. B., McLaren, A. J., and Hunke, E. C.: Design and implementation of the infrastructure of HadGEM3: the nextgeneration Met Office climate modelling system, Geosci. Model Dev., 4, 223-253, doi:10.5194/gmd-4-223-2011, 2011.

Hibler, W.: Modeling the formation and evolution of oriented fractures in sea ice, Ann. Glaciol., 33, 157-164, 2001.

Hibler III, W. D.: A dynamic thermodynamic sea ice model, J. Phys. Oceanogr., 9, 815-843, 1979.

Higginson, S., Thompson, K. R., Huang, J., Vëronneau, M., and Wright, D. G.: The mean surface circulation of the North Atlantic subpolar gyre: A comparison of estimates derived from new gravity and oceanographic measurements, J. Geophys. Res., 116, C08016, doi:10.1029/2010JC006877, 2011.

Holloway, G. and Wang, Z.: Representing eddy stress in an Arctic Ocean model, J. Geophys. Res., 114, C06020, doi:10.1029/2008JC005169, 2009.

Hunke, E. C.: Viscous-plastic sea ice dynamics with the EVP model: linearization issues, J. Comput. Phys., 170, 18-38, 2001.

Hunke, E. C. and Dukowicz, J. K.: An elastic-viscous-plastic model for sea ice dynamics, J. Phys. Oceanogr., 27, 1849-1867, 1997. 
Hunke, E. C. and Dukowicz, J. K.: The elastic-viscous-plastic sea ice dynamics model in general orthogonal curvilinear coordinates on a sphere-incorporation of metric terms, Mon. Weather Rev., 130, 1848-1865, 2002.

Hunke, E. C. and Lipscomb, W. H.: CICE: the Los Alamos Sea Ice Model Documentation and Software User's Manual, Tech. rep., Los Alamos National Laboratory, 2010.

Jakobson, E., Vihma, T., Palo, T., Jakobson, L., Keernik, H., and Jaagus, J.: Validation of atmospheric reanalyses over the central Arctic Ocean, Geophys. Res. Lett., 39, L10802, doi:10.1029/2012GL051591, 2012.

Kwok, R. and Morison, J.: Dynamic topography of the ice-covered Arctic Ocean from ICESat, Geophys. Res. Lett., 38, L02501, doi:10.1029/2010GL046063, 2011.

Kwok, R., Cunningham, G., and Pang, S.: Fram Strait sea ice outflow, J. Geophys. Res.-Oceans, 109, C01009, doi:10.1029/2003JC001785, 2004.

Kwok, R., Cunningham, G. F., Wensnahan, M., Rigor, I., Zwally, H. J., and Yi, D.: Thinning and volume loss of Arctic sea ice cover: 2003-2008, J. Geophys. Res., 114, C07005, doi:10.1029/2009JC005312, 2009.

Laxon, S., Giles, K. A., Ridout, A. L., Wingham, D. J., Willatt, R., Cullen, R., Kwok, R., Schweiger, A., Zhang, J., Haas, C., Hendricks, S., Krishfield, R., Kurtz, N., Farrell, S., and Davidson, M.: CryoSat-2 estimates of Arctic sea ice thickness and volume, Geophys. Res. Lett., 40, 1-6, doi:10.1002/GRL.50193, 2013.

Lemieux, J.-F., Beaudoin, C., Dupont, F., Roy, F., Smith, G. C., Shlyaeva, A., Buehner, M., Caya, A., Chen, J., Carrieres, T., Pogson, L., DeRepentigny, P., Plante, A., Pestieau, P., Pellerin, P., Ritchie, H., Garric, G., and Ferry, N.: The Regional Ice Prediction System (RIPS): verification of forecast sea ice concentration, Q. J. Roy. Meteorol. Soc., doi:10.1002/qj.2526, in press, 2015a.

Lemieux, J.-F., Tremblay, L. B., Dupont, F., Plante, M., Smith, G. C., and Dumont, D.: A basal stress parameterization for modeling landfast ice, J. Geophys. Res.-Oceans, 120, 3157-3173, doi:10.1002/2014JC010678, 2015b.

Lipscomb, W. H., Hunke, E. C., Maslowski, W., and Jakacki, J.: Ridging, strength, and stability in high-resolution sea ice models, J. Geophys. Res., 112, C03S91, doi:10.1029/2005JC003355, 2007.

Lique, C., Garric, G., Treguier, A.-M., Barnier, B., Ferry, N., Testut, C.-E., and Girard-Ardhuin, F.: Evolution of the Arctic Ocean Salinity, 2007-2008: Contrast between the Canadian and the Eurasian Basins, J. Climate, 24, 1705-1717, doi:10.1175/2010JCLI3762.1, 2011.

Lu, Y., Higginson, S., Nudds, S., and Prinsenberg, S.: Model simulated volume fluxes through the Canadian Arctic Archipelago and Davis Strait: Linking monthly variations to forcing in different seasons, J. Geophys. Res.-Oceans, 119, 1927-1942, doi:10.1002/2013JC009408, 2014.

Lumpkin, R. and Johnson, G. C.: Global ocean surface velocities from drifters: Mean, variance, El Niño-Southern Oscillation response, and seasonal cycle, J. Geophys. Res., 118, 1-15, doi:10.1002/jgrc.20210, 2013.

Madec, G. and NEMO team: NEMO ocean engine, Tech. rep., Note du Pole de Modelisation, 27, Institut Pierre-Simon Laplace, 11, 2008.
Madec, G., Delecluse, P., Imbard, M., and Lévy, C.: OPA 8.1. Ocean General Circulation Model reference manual, Tech. rep., Note du Pole de Modelisation, Institut Pierre-Simon Laplace, 11, 1998.

Masson-Delmotte, V., Kageyama, M., Braconnot, P., Charbit, S., Krinner, G., Ritz, C., Guilyardi, E., Jouzel, J., Abe-Ouchi, A., Crucifix, M., Gladstone, R. M., Hewitt, C. D., Kitoh, A., LeGrande, A. N., Marti, O., Merkel, U., Motoi, T., Ohgaito, R., Otto-Bliesner, B., Peltier, W. R., Ross, I., Valdes, P. J., Vettoretti, G., Weber, S. L., Wolk, F., and Yu, Y.: Past and future polar amplification of climate change: climate model intercomparisons and ice-core constraints, Clim. Dynam., 26, 513-529, doi:10.1007/s00382-005-0081-9, 2006.

Massonnet, F., Fichefet, T., Goosse, H., Vancoppenolle, M., Mathiot, P., and König Beatty, C.: On the influence of model physics on simulations of Arctic and Antarctic sea ice, The Cryosphere, 5, 687-699, doi:10.5194/tc-5-687-2011, 2011.

Maykut, G. A. and McPhee, M. G.: Solar heating of the Arctic mixed layer, J. Geophys. Res., 100, 24691-24703, 1995.

McPhee, M. G.: Ice-ocean momentum transfer for the AIDJEX ice model, AIDJEX Bulletin, 29, 93-111, 1975.

Megann, A., Storkey, D., Aksenov, Y., Alderson, S., Calvert, D., Graham, T., Hyder, P., Siddorn, J., and Sinha, B.: GO5.0: the joint NERC-Met Office NEMO global ocean model for use in coupled and forced applications, Geosci. Model Dev., 7, 10691092, doi:10.5194/gmd-7-1069-2014, 2014.

Morison, J., Aagaard, K., Falkner, K. K., Hatakeyama, K., Moritz, R., Overland, J. E., Perovich, D., Shimada, K., Steele, M., Takizawa, T., and Woodgate, R.: North Pole Environmental Observatory delivers early results, EOS T. Am. Geophys. Un., 83, 357361, doi:10.1029/2002EO000259, 2002.

Pickart, R. S., McKee, T. K., Torres, D. J., and Harrington, S.: Mean structure and interannual variability of the Slope Water System south of Newfoundland, J. Phys. Oceanogr., 29, 25412558, 1999.

Polashenski, C., Perovich, D., Richter-Menge, J., and Elder, B.: Seasonal ice mass-balance buoys: adapting tools to the changing Arctic, Ann. Glaciol., 52, 18-26, 2011.

Proshutinsky, A., Krishfield, R., Timmermans, M.-L., Toole, J., Carmack, E., McLaughlin, F., Williams, W. J., Zimmermann, S., Itoh, M., and Shimada, K.: Beaufort Gyre freshwater reservoir: State and variability from observations, J. Geophys. Res., 114, C00A10, doi:10.1029/2008JC005104, 2009.

Rattan, S., Myers, P. G., Treguier, A.-M., Theetten, S., Biastoch, A., and Böning, C.: Towards an understanding of Labrador Sea salinity drift in eddy-permitting simulations, Ocean Model., 35, 77-88, doi:10.1016/j.ocemod.2010.06.007, 2010.

Rio, M. H., Guinehut, S., and Larnicol, G.: New CNES-CLS09 global mean dynamic topography computed from the combination of GRACE data, altimetry, and in situ measurements, J. Geophys. Res., 116, C07018, doi:10.1029/2010JC006505, 2011.

Rothrock, D. A.: The Energetics of the Plastic Deformation of Pack Ice by Ridging, J. Geophys. Res., 33, 4514-4519, 1975.

Roy, F., Chevallier, M., Smith, G., Dupont, F., Garric, G., and Lemieux, J.-F.: Arctic sensitivity to the atmosphere-iceocean boundary layer in global simulations, J. Geophys. Res., doi:10.1002/2014JC010677, online first, 2015.

Saenko, O. A., Dupont, F., Yang, D., Myers, P. G., Yashayaev, I., and Smith, G. C.: Role of resolved and parameterized eddies in the 
Labrador Sea balance of heat and buoyancy, J. Phys. Oceanogr., 44, 3008-3032, doi:10.1175/JPO-D-14-0041.1, 2014.

Schauer, U., Fahrbach, E., Osterhus, S., and Rohardt, G.: Arctic warming through the Fram Strait: Oceanic heat transport from 3 years of measurements, J. Geophys. Res., 109, C06026, doi:10.1029/2003JC001823, 2004.

Schauer, U., Beszczynska-Möller, A., Walczowski, W., Fahrbach, E., Piechura, J., and Hansen, E.: Variation of measured heat flow through the fram strait between 1997 and 2006, in: arcticsubarctic ocean fluxes, edited by: Dickson, R., Meincke, J., and Rhines, P., pp. 65-85, Springer Netherlands, doi:10.1007/978-14020-6774-7_4, 2008.

Smith, G. C., Roy, F., and Brasnett, B.: Evaluation of an operational ice-ocean analysis and forecasting system for the Gulf of St Lawrence, Q. J. Roy. Meteorol. Soc., 139, 419-433, doi:10.1002/qj.1982, 2012.

Smith, G. C., Roy, F., Mann, P., Dupont, F., Brasnett, B., Lemieux, J.-F., Laroche, S., and Belair, S.: A new atmospheric dataset for forcing ice-ocean models: Evaluation of reforecasts using the Canadian global deterministic prediction system, Q. J. Roy. Meteorol. Soc., 140, 881-894, doi:10.1002/qj.2194, 2014.

Smith, G. C., Roy, F., Reszka, M., Colan, D. S., He, Z., Deacu, D., Belanger, J.-M., Skachko, S., Liu, Y., Dupont, F., JeanFranc, L., Beaudoin, C., Tranchant, B., Drevillon, M., Garric, G., Testut, C.-E., Lellouche, J.-M., Pellerin, P., Ritchie, H., Lu, Y., and Davidson, F.: Sea ice Forecast Verification in the Canadian Global Ice Ocean Prediction System, Q. J. Roy. Meteorol. Soc., doi:10.1002/qj.2555, online first, 2015.

Steele, M.: Sea ice melting and floe geometry in a simple ice-ocean model, J. Geophys. Res., 97, 17729-17738, 1992.

Steele, M., Morison, J., Ermold, W., Rigor, I., Ortmeyer, M., and Shimada, K.: Circulation of summer Pacific halocline water in the Arctic Ocean, J. Geophys. Res., 109, C02027, doi:10.1029/2003JC002009, 2004.

Talley, L., Pickard, G., Emery, W., and Swift, J.: Descriptive physical oceanography: an introduction, 6th Edn., Academic Press, London, 2011.

Thompson, K. and Demirov, E.: Skewness of sea level variability of the world's oceans, J. Geophys. Res., 111, C05005, doi:10.1029/2004JC002839, 2006.
Tsamados, M., Feltham, D. L., and Wilchinsky, A. V.: Impact of a new anisotropic rheology on simulations of Arctic sea ice, J. Geophys. Res., 118, 91-107, doi:10.1029/2012JC007990, 2013.

Tsamados, M., Feltham, D. L., Schroeder, D., Flocco, D., Farrell, S. L., Kurtz, N., Laxon, S. W., and Bacon, S.: Impact of Variable Atmospheric and Oceanic Form Drag on Simulations of Arctic Sea Ice, J. Phys. Oceanogr., 44, 1329-1353, doi:10.1175/JPO-D13-0215.1, 2014.

Turner, A. K. and Hunke, E. C.: Impacts of a mushy-layer thermodynamic approach in global sea-ice simulations using the CICE sea-ice model, J. Geophys. Res.-Oceans, 120, 1253-1275, doi:10.1002/2014JC010358, 2015.

Umlauf, L. and Burchard, H.: A generic length-scale equation for geophysical turbulence models, J. Mar. Res., 61, 235-265, 2003.

Vancoppenolle, M., Fichefet, T., and Goosse, H.: Simulating the mass balance and salinity of Arctic and Antarctic sea ice. 2. Importance of sea ice salinity variations, Ocean Model., 27, 54-69, 2009a.

Vancoppenolle, M., Fichefet, T., Goosse, H., Bouillon, S., Madec, G., and Morales Maqueda, M.: Simulating the mass balance and salinity of Arctic and Antarctic sea ice. 1. Model description and validation, Ocean Model., 27, 33-53, doi:10.1016/j.ocemod.2008.10.005, 2009b.

Vertenstein, M., Craig, T., Henderson, T., Murphy, S., Carr Jr., G. R., and Norton, N.: CCSM3.0 User's Guide, UCAR, available at: www.cesm.ucar.edu/ccsm3.0 (last access: 13 May 2015), 2004.

Wang, Z., Lu, Y., Wright, D., and Dupont, F.: Sea ice sensitivity to the parameterisation of open water area, J. Oper. Ocean., 3, 3-9, 2010.

Zhang, J. and Rothrock, D. A.: Modeling global sea ice with a thickness and enthalpy distribution model in generalized curvilinear coordinates, Mon. Weather Rev., 131, 845-861, 2003.

Zhang, J. and Steele, M.: Effect of vertical mixing on the Atlantic Water layer circulation in the Arctic Ocean, J. Geophys. Res.Oceans, 112, C04S04, doi:10.1029/2006JC003732, 2007.

Zhu, J., Demirov, E., Dupont, F., and Wright, D.: Eddy-permitting simulations of the sub-polar North Atlantic: impact of the model bias on water mass properties and circulation, Ocean Dynam., 60, 1177-1192, 2009. 